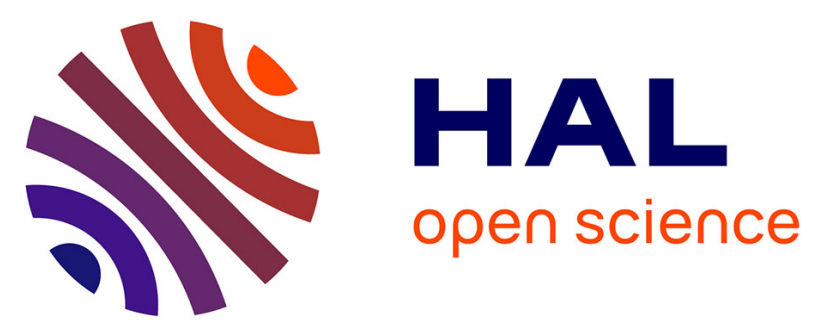

\title{
Anthropogenic aerosol emissions mapping and characterization by imaging spectroscopy - application to a metallurgical industry and a petrochemical complex
}

Yannick Philippets, Pierre-Yves Foucher, Rodolphe Marion, Xavier Briottet

\section{- To cite this version:}

Yannick Philippets, Pierre-Yves Foucher, Rodolphe Marion, Xavier Briottet. Anthropogenic aerosol emissions mapping and characterization by imaging spectroscopy - application to a metallurgical industry and a petrochemical complex. International Journal of Remote Sensing, 2018, 4 (1), pp.1-43. 10.1080/01431161.2018.1513665 . hal-02118857

\section{HAL Id: hal-02118857 \\ https://hal.science/hal-02118857}

Submitted on 15 Oct 2021

HAL is a multi-disciplinary open access archive for the deposit and dissemination of scientific research documents, whether they are published or not. The documents may come from teaching and research institutions in France or abroad, or from public or private research centers.
L'archive ouverte pluridisciplinaire HAL, est destinée au dépôt et à la diffusion de documents scientifiques de niveau recherche, publiés ou non, émanant des établissements d'enseignement et de recherche français ou étrangers, des laboratoires publics ou privés. 


\title{
Anthropogenic aerosol emissions mapping and characterization by imaging spectroscopy - application to a metallurgical industry and a petrochemical complex
}

\author{
Yannick Philippets ${ }^{\mathrm{a}}$, Pierre-Yves Foucher $\mathbb{D}^{\mathrm{b}}{ }^{\mathrm{b}}$, Rodolphe Marion $\mathbb{D}^{\mathrm{a}}$ and \\ Xavier Briottet $\mathbb{1}^{\mathrm{b}}$
}

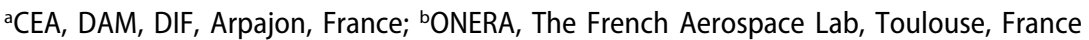

\begin{abstract}
This paper is focused on the retrieval of industrial aerosol optical thickness (AOT) and microphysical properties by means of air-borne imaging spectroscopy. Industrial emissions generally lead to optically thin plumes requiring an adapted detection method taking into account the weak proportion of particles sought in the atmosphere. To this end, a semi-analytical model combined with the Cluster-Tuned Matched Filter (CTMF) algorithm is presented to characterize those plumes, requiring the knowledge of the soil under the plume. The model allows the direct computation of the at-sensor radiance when a plume is included in the radiative transfer. When applied to industrial aerosol classes as defined in this paper, simulated spectral radiances can be compared to 'real' MODTRAN (Moderate Resolution Atmospheric Transmission) radiances using the Spectral Angle Mapper (SAM). On the range from 0.4 to $0.7 \mu \mathrm{m}$, for three grounds (water, vegetation, and bright one), SAM scores are lower than 0.043 in the worst case (a both absorbing and scattering particle over a bright ground), and usually lower than 0.025 . The darker the ground reflectance is, the more accurate the results are (typically for reflectance lower than 0.3). Concerning AOT retrieval capabilities, with a pre-calcu-lated model for a reference optical thickness of 0.25 , we are able to retrieve plume AOT at $550 \mathrm{~nm}$ in the range 0.0 to 0.4 with an error usually ranging between $9 \%$ and $13 \%$. The first test case is a CASI (Compact Airborne Spectrographic Imager) image acquired over the metallurgical industry of Fos-sur-Mer (France). First results of the use of the model coupled with CTMF algorithm reveal a scattering aerosol plume with particle sizes increasing with the distance from the stack (from detection score of $54 \%$ near the stack for particles with a diameter of $0.1 \mu \mathrm{m}$, to $69 \%$ away from it for $1.0 \mu \mathrm{m}$ particles). A refinement is made then to estimate more precisely aerosol plume properties, using a multimodal distribu-tion based on the previous results. It leads to find a mixture of sulfate and brown carbon particles with a plume AOT ranging between 0.2 and 0.5 . The second test case is an AHS (Airborne Hyperspectral Scanner) image acquired over the petrochemical site of Antwerp (Belgium). The first CTMF application results in detecting a brown carbon aerosol of $0.1 \mu \mathrm{m}$ mode (detection score is $51 \%$ ). Refined results show the evolution of the AOT decreasing from 0.15 to 0.05 along the plume for a mixture of brown carbon fine mode and $0.3 \mu \mathrm{m}$ radius of sulfate aerosol.
\end{abstract}




\section{Introduction}

Remote sensing tools have been widely used over the past twenty years to study atmospheric composition, in particular, aerosols (King et al. 1999). These particles suspended in the atmosphere have a major role in the Earth's global radiation budget, as reported by the IPCC (Intergovernmental Panel on Climate Change), and their study is essential for a better comprehension of climate change (Artaxo et al. 2013). Many satellite products, from both passive and active sensors, have been developed to build maps of aerosol optical thickness (AOT) at a global or regional scale (Jeong et al. 2003; Veefkind et al. 2011; Hsu et al. 2012). From Charlson et al. (1992) to Artaxo et al. (2013), anthropogenic aerosols are pointed out their cooling impact in radiative forcing. In fact, they have both a direct effect by scattering the solar radiations and an indirect effect by changing the reflective properties of clouds. Koller (2015) estimates that anthropogenic aerosols are representing about $10 \%$ of the total mass of pollutants (gases and aerosols) rejected into the atmosphere. These aerosols are involved in several pollution events with various components deriving from them, such as particulate matter with a diameter between 2.5 and $10 \mu \mathrm{m}$ (also known as PM10) or smog. Existing sensors enabling to characterize aerosols from space are, for example, the Advanced Very High-Resolution Radiometer - AVHRR (Riffler et al. 2010), the Moderate-resolution Imaging Spectrometer - MODIS (Levy et al. 2013), or the Cloud-Aerosol Lidar with Orthogonal Polarization CALIOP (Winker et al. 2010). Their spatial resolution is ranging from $300 \mathrm{~m}$ to $1 \mathrm{~km}$, and so does not allow studying industrial aerosols close to their emission points, which requires a finer spatial resolution to resolve the emitted plume, while these anthropogenic particles are precisely the least known component in the radiative forcing of climate change (Andreae et al. 2001).

Firstly, a finer spatial resolution can be obtained by using airborne sensors, whose metric or decametric resolution is adapted to the spatial extent of industrial plumes and industrial sites. Secondly, within the family of remote sensing instruments, hyperspectral sensors (or imaging spectrometers) have an interesting potential for the characterization of industrial aerosols. Indeed, the spectral domain covered by these sensors, from 0.4 to $2.5 \mu \mathrm{m}$ (reflective domain), contains the one where aerosols particularly impact the measures, before $1 \mu \mathrm{m}$. A single acquisition makes it possible to obtain information about gases, aerosols, and soil properties together. The high spatial resolution of these airborne instruments allows studies at the level of the emission source (Deschamps et al. 2012). Therefore, in this study, airborne hyperspectral imaging in the visible and nearinfrared regions is used to characterize aerosol plumes, and in particular to retrieve the main type of particles, as well as to estimate their microphysical properties and optical thicknesses. Note that we only focus on characterizing the observed aerosol plumes. Nevertheless, it may be also necessary to correct their effect for accurate gas retrieval. Indeed, the presence of aerosols in plumes may induce large errors on gas detection, as shown by Marion, Michel, and Faye (2004) and Deschamps et al. (2013) for carbon 
dioxide $\left(\mathrm{CO}_{2}\right)$, by Buchwitz et al. (2006) for carbon monoxide (CO) and methane $\left(\mathrm{CH}_{4}\right)$ or by Leitão et al. (2010) for nitrogen dioxide $\left(\mathrm{NO}_{2}\right)$.

Several methods have already been developed for the study of aerosols, for detection, identification or quantification. The dark pixel method requires a dark area in the image such as vegetation to estimate a relative atmospheric scattering model to predict haze values (Chavez 1988). The reducing contrast method DDV (for Dark Dense Vegetation) compares two images of a same scene, one in clear-sky conditions and one with an aerosol plume (Kaufman 1987). The MODIS instrument benefits from an operational AOT retrieval method named as the Collection 6 dark target (DT) algorithm (Levy et al. 2013), then enhanced by a ridge regression model proposed by Hang et al. (2018). All these conditions are not necessarily gathered on an industrial scene: the presence of dark vegetation is not guaranteed for this kind of environment, as well as the availability of multi-temporal hyperspectral images (especially in the case of airborne campaigns), and the variability of aerosol concentrations from one pixel to another does not ensure the hypothesis of invariance of atmospheric phenomena. Look-up tables (LUT) based methods are frequently used to study aerosols in addition to analytical models. Alakian, Marion, and Briottet (2009) considered the retrieval of microphysical and optical properties of aerosol plumes (from industrial origin or biomass burning from forest fires), and proposed the L-APOM (LUT Aerosol Plume Optical Model) method, based on Alakian et al. (2008), to model the radiative terms (reflectance, transmittance, and spherical albedo of the atmosphere) as a function of the optical thickness. Typical optical thickness values were set from 1 to 5 , which correspond to thick biomass plumes. Deschamps et al. (2012) focused more specifically on industrial aerosols. They proposed a method based on pixel pairs located in the transition between two kinds of ground or between an illuminated area and a shadowed one (with the same ground reflectance), in order to compare estimated AOT and pre-calculated AOT from a LUT. This method is adapted to cases where the optical thickness values are between 0.2 and 1.5. Two limitations appear: this method requires a manual selection of the pixel pairs and has an important sensitivity to the determination of the soil reflectance under the plume. It is necessary to have a fine spatial resolution (about $1 \mathrm{~m}$ ) in order to find pure pixels under the plume.

We are in particular interested in retrieving optically thin aerosol plumes emitted by stacks. This is why we chose to work with a filter able to detect these low concentrations of target aerosols in a background and with a lower sensitivity to background knowledge. Recently, the matched filtering algorithm CTMF (Cluster-Tuned Matched Filter), introduced by Funk et al. (2001), has been applied with success to detect gaseous plumes from airborne hyperspectral images. Thorpe et al. (2012) first worked on the detection of anomalies of $\mathrm{CO}_{2}, \mathrm{CH}_{4}$ and $\mathrm{N}_{2} \mathrm{O}$ (nitrous oxide) on hydrocarbon storage tanks or natural marine seeps offshore. Then, Dennison et al. (2013) measured anomalies of $\mathrm{CO}_{2}$ as low as $100 \mathrm{ppm}$ on an AVIRIS image (Airborne Visible/Infrared Imaging Spectrometer, Green et al. 1998) and 25 ppm on an AVIRIS-NG image (AVIRIS Next Generation, detailed in Hamlin et al. 2010). Thorpe et al. (2013) used the CTMF to detect $\mathrm{CH}_{4}$ anomalies, for concentrations up to $45.5 \mathrm{ppm}$ measured on AVIRIS scenes. Based on a linear model of the radiance, composed of a background signal and a target signal (the target being the gas of interest to detect in the pixel), the filter is computed for each background class resulting from a $k$-means classification (MacQueen 1957) and adapted 
to the ground via the class correlation matrix and to the target via a specific signature. Each matched filter is then applied to the differential radiance between 'on-plume' and 'off-plume' radiances to obtain a detection score, as high as the target signature corresponds to the signal.

\section{Classification of industrial aerosols}

We present in this section a classification of industrial aerosols that will be used for the first step of the retrieval. To describe the impact of anthropogenic particles in an industrial environment including those emitted by industries, most of the studies uses a general model, since IPCC has retained five large aerosol families for global studies (Andreae et al. 2001; Kaufman, Tanré, and Boucher 2002): soot, sulfate, water soluble, dust-like, and oceanic aerosols. For example, Kneizys et al. (1996) defined, for the MODTRAN (Moderate Resolution Atmospheric Transmission) radiative transfer code, the 'urban/industrial aerosol' as a mixture of $80 \%$ rural aerosols and $20 \%$ carbonaceous aerosols, combining the size distribution of the rural ones and the refractive index of the carbonaceous ones. But releases of industries usually cover a wide range of chemical compounds with very different microphysical properties. To differentiate them, we plan to use the differences in their radiative behaviours. Because these emitted particles are relatively unknown at the scale of interest, a specific classification of the most representative families of aerosols released by observed industrial sites needs to be provided. The one presented in the following paragraph is inspired by Penning de Vries et al. (2015), defining aerosol types by their size (small, medium or large) and their absorption in the ultraviolet range (non-absorbing, neutral or absorbing).

Firstly, this classification distinguishes four families of releases, according to their carbon content and their scattering or absorbing properties (i.e. the colour of the plume), as detailed in Table 1. At a second level, for each family, three classes are defined (except for liquid water, for which only one has been defined), corresponding to three modes (one fine mode, one accumulation mode and one coarse mode) characterized by a modal radius and a standard deviation, as for Penning de Vries et al. (2015). This forms the ten classes (from the four families in Table 1) used in this study. It is important to note that this classification is not intended to be exhaustive, which is impossible given the variability of the properties for the aerosols anyway (Wen 1996; Herbin and Dubuisson 2016). Two criteria have been taken into account. Firstly, these classes must be the most representative of major industrial releases. Secondly, each class

Table 1. Refractive indexes chosen to define the four families of the aerosol classification.

\begin{tabular}{lll}
\hline Family & \multicolumn{1}{c}{ Aerosol type } & \multicolumn{1}{c}{ Reference for the refractive index } \\
\hline Absorbing aerosols & Soot (black carbon) & Fenn et al. (1985) \\
Scattering aerosols & Sulfate aerosol $\left(\mathrm{H}_{2} \mathrm{SO}_{4}\right)$ & Quinn et al. (1995) \\
Intermediate behaviour aerosols & Brown carbon & $\begin{array}{l}\text { Real part: Hoffer et al. (2006) } \\
\text { Imaginary part: Feng, Ramanathan, and Kotamarthi (2013) }\end{array}$ \\
Liquid water droplets & Liquid water & Irvine and Pollack (1968) \\
\hline
\end{tabular}


must have a radiative impact sufficiently different from each other to be detected and classified by a hyperspectral sensor (as illustrated by Figure 5).

Aerosol particles are defined, from a physical point of view, by a set of three parameters named as microphysical properties: the chemical composition (characterized by the complex refractive index), the size distribution (defined by a radius and its standard deviation) and the shape. At a local industrial site scale, aerosol properties can vary temporally and spatially very quickly (Deschamps et al. 2012).

For the first step of our classification, we define three main families (presented into the first column of the Table 1), depending on their carbon content and their main scattering characteristics, in a similar way to Penning de Vries et al. (2015): absorbing aerosols (black smokes), scattering aerosols (white plumes) and aerosols with intermediate behaviour (trying to differentiate brown carbon). We add liquid water as a fourth family (in theory not defined as an aerosol but more like a hydrometeor, as explained by Jacobson (2002)). It is used to determine if the model developed hereafter can distinguish it from usual scattering aerosols as organic carbon or sulfates, which produce also white plumes on RGB images. The first microphysical parameter used to define the aerosol families is the refractive index (taken from the literature, see Table 1).

Absorbing aerosols result from the combustion of coal for energy production. They are usually confused with soot particles, or black carbon which is the main particle responsible for absorption (Ocko et al. 2012). The complex refractive index of black

(a)

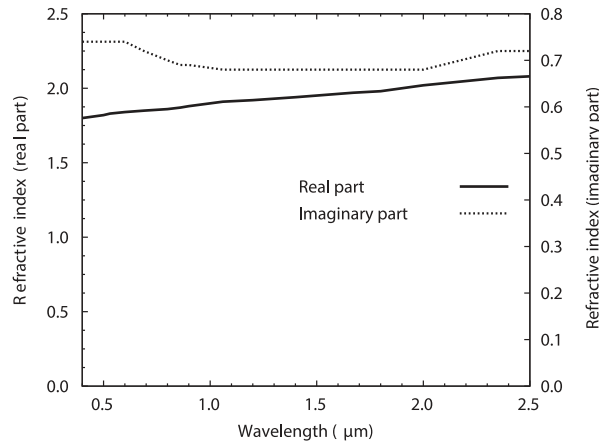

(c)

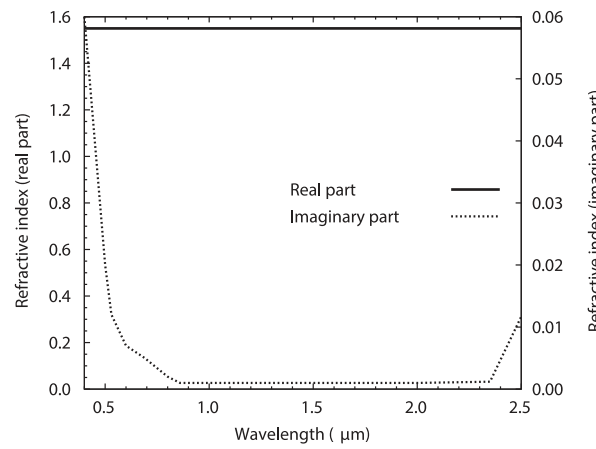

(b)

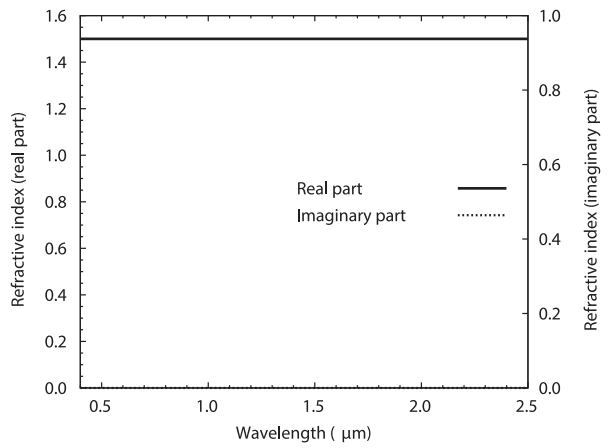

(d)

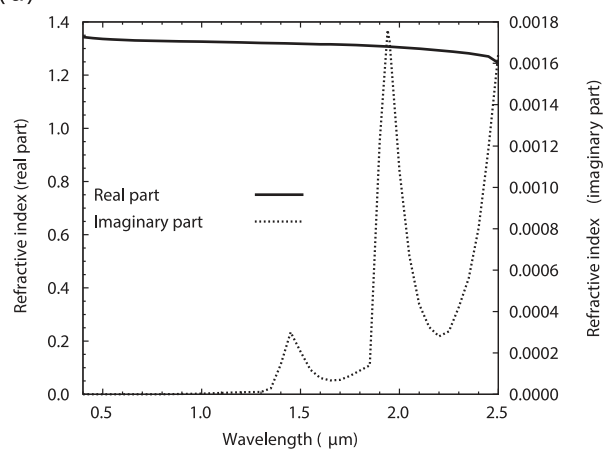

Figure 1. Complex refractive indexes used for the four industrial aerosol families: (a) absorbing aerosol; (b) scattering aerosol; (c) brown carbon; (d) liquid water. 
carbon taken from Fenn et al. (1985) gives to this pure absorbing particle both non-zero real and imaginary parts (Figure 1(a)).

At the opposite side in terms of radiative behaviour, scattering aerosols are mainly composed of sulfates, nitrates, and organic carbon materials. This family is represented here by sulfate, the typical dominant scattering particle (Ocko et al. 2012). Unlike soot, its imaginary part is zero all over the spectral domain of interest (Figure 1(b)).

Recent studies (Andreae and Gelencsér 2006; Bond et al. 2013) highlighted the importance of a third carbon-based compound with an intermediate behaviour, between the two previous families: brown carbon, which is also known as 'light-absorbing organic carbon'. It is mostly produced by tar materials from smouldering fires or coal combustion. It distinguishes itself by a high absorption in the ultraviolet domain (described by a non-zero imaginary part of the refractive index), and a high scattering in the near infrared region (after $0.8 \mu \mathrm{m}$ ), given its characteristic brownish colour (Figure 1(c)).

For liquid water, only one set of microphysical properties is considered, according to Auer (1976) observations about liquid water plumes from industrial plants which are modelled as cumulus. The complex refractive index has a behaviour similar to the sulfate one here - and therefore to the scattering family (here the mode should differentiate them with this modelling) -, except in the infrared domain where the imaginary part exhibits peaks (near 1.4 and $1.9 \mu \mathrm{m}$ ) characteristic of the water molecule $\mathrm{H}_{2} \mathrm{O}$ in liquid form (Figure 1(d)).

The second microphysical parameter is the size distribution, assuming that aerosol sizes can be represented by a lognormal distribution, which is defined with two parameters (the radius $r_{\mathrm{m}}$ and its associated standard deviation $\sigma_{\mathrm{m}}$ ). It represents the probability of presence of a particle whose radius would be between $r$ and $r+d r$, as involved in the following expression:

$$
\left.N(r)=\frac{N_{0}}{\sqrt{2 \pi} r \ln \left(\sigma_{\mathrm{m}}\right)} \exp -\frac{\ln ^{2}\left(r / r_{\mathrm{m}}\right)}{\sqrt{2} \ln ^{2}\left(\sigma_{\mathrm{m}}\right)}\right)
$$

where $N_{0}$ is the total number of particles per unit volume.

It is used to separate each family into three classes, which are, respectively, the fine mode $\left(r_{\mathrm{m}}=0.1 \mu \mathrm{m}\right.$ and $\left.\sigma_{\mathrm{m}}=1.2\right)$, the accumulation mode $\left(r_{\mathrm{m}}=0.5 \mu \mathrm{m}\right.$ and $\left.\sigma_{\mathrm{m}}=1.5\right)$ and the coarse mode $\left(r_{\mathrm{m}}=1 \mu \mathrm{m}\right.$ and $\left.\sigma_{\mathrm{m}}=2\right)$. The liquid water family has just one particular mode $\left(r_{\mathrm{m}}=4 \mu \mathrm{m}\right.$ and $\left.\sigma_{\mathrm{m}}=2\right)$ corresponding to the mean values retained by Hess, Koepke, and Schult (1998) for the software package OPAC (Optical Properties of Aerosols and Clouds). It is important to keep in mind here that it is a huge simplification to model water droplets in a plume. Weickmann and aufm Kampe (1953) detailed the large spectra of droplets radii while predicting visible plume dimensions, and plume rise was especially carried out by Hanna, Briggs, and Hosker (1982). Finally, ten classes are thus formed from the four families.

The third microphysical parameter is the shape of the particles. For the rest of this study, we consider industrial aerosols as spherical particles with homogeneous composition, in order to apply the theory developed by Mie (1908) for the computation of optical properties. Although this is not the case in practice, Pujol, Brogniez, and Labonnote (2012) demonstrated for plume particles with low dissymmetry and/or randomly orientated, that scattering is averaged and that the error due to the Mie 
modelling is quite small. To do so, we use the concept of aerodynamic radius or equivalent radius, which is the radius of a hypothetical spherical sphere with the same motion characteristics than the observed aerosol (Vincent 1995). By language abuse, the term radius (respectively diameter) corresponds in this study to the equivalent radius (respectively equivalent diameter).

Masclet (2005) indicates that in urban environment, mix of pollution aerosols and natural aerosols usually results in two or three granulometric modes, and in low pollution areas (such as oceanic places), only one mode distribution can be observed (although some marine models have up to four modes). However, the hypothesis of considering monomodal particles is maintained in the beginning of this work, the study of aerosols composed of two or more modes being the scope of the last part of this paper.

Considering the wide variability of microphysical properties for the families defined previously and the limited data available at our study scale, radii and standard deviations for each class were chosen not for their veracity at first, but for their distinct induced radiative behaviours as seen by the sensor.

The optical properties (extinction coefficient, spherical albedo, and asymmetry factor) of each class are deduced from microphysical properties with a computation tool based on 'bhmie' code from Bohren and Huffman (1983) in order to apply the Mie theory. Thereby, we can compute with MODTRAN radiance values with or without an aerosol plume as it is measured by the sensor.

\section{Semi-analytical modelling of the aerosol plume radiative impact}

\subsection{Model derivation}

Our objective here is to present, from the radiative transfer equation describing an atmosphere with an aerosol plume, the differential at-sensor radiance as the product of the aerosol optical depth and an aerosol spectral signature, a formulation adapted to the CTMF filter (see paragraph 4.4.1). This model is based on some assumptions that will be discussed in subsection 3.2.

Assuming a homogeneous, flat, and Lambertian ground, the monochromatic radiance acquired by a hyperspectral sensor $L^{\text {sensor }}(\lambda)$ is given in the reflective domain by Chandrasekhar (1960) as

$$
L^{\text {sensor }}(\lambda)=L^{\text {atm }}(\lambda)+\frac{E^{\text {surf }}(\lambda) T^{\text {atm }}(\lambda) \rho_{\text {soil }}(\lambda)}{\pi\left(1-\rho_{\text {soil }}(\lambda) S^{\text {atm }}(\lambda)\right)}
$$

where $\lambda$ stands for the wavelength, $L^{\operatorname{atm}}(\lambda)$ is the upwelling atmospheric radiance between the surface and the sensor, $E^{\text {surf }}(\lambda)$ is the total downwelling (direct plus diffuse) irradiance at the surface, $T^{\mathrm{atm}}(\lambda)$ is the total upward (direct plus diffuse) transmittance of the atmosphere, $\rho_{\text {soil }}(\lambda)$ is the ground reflectance and $S^{\text {atm }}(\lambda)$ is the spherical albedo of the atmosphere.

In the presence of an aerosol plume, all of these radiative terms $L^{\text {atm }}(\lambda), E^{\text {surf }}(\lambda)$, $T^{\text {atm }}(\lambda)$ and $S^{\text {atm }}(\lambda)$ are modified and then respectively written as $L_{\text {plume }}^{\text {atm }}(\lambda), E_{\text {plume }}^{\text {surf }}(\lambda)$, $T_{\text {plume }}^{\text {atm }}(\lambda)$ and $S_{\text {plume }}^{\text {atm }}(\lambda)$. Assuming an infinite plume layer above the surface, equation (2) is rewritten as 


$$
L_{\text {plume }}^{\text {sensor }}(\lambda)=L_{\text {plume }}^{\text {atm }}(\lambda)+\frac{E_{\text {plume }}^{\text {surf }}(\lambda) T_{\text {plume }}^{\text {atm }}(\lambda) \rho_{\text {soil }}(\lambda)}{\pi \cdot\left(1-\rho_{\text {soil }}(\lambda) S_{\text {plume }}^{\text {atm }}(\lambda)\right)}
$$

The radiative terms of equations (2) and (3) are assumed to be linked by the following relationships:

$$
\begin{aligned}
& L_{\text {plume }}^{\text {atm }}(\lambda)=L^{\text {atm }}(\lambda)+\Delta L_{\text {plume }}^{\text {atm }}(\lambda) \\
& E_{\text {plume }}^{\text {surf }}(\lambda)=E^{\text {surf }}(\lambda)+\Delta E_{\text {plume }}^{\text {surf }}(\lambda) \\
& T_{\text {plume }}^{\text {atm }}(\lambda)=T^{\text {atm }}(\lambda)+\Delta T_{\text {plume }}^{\text {atm }}(\lambda) \\
& S_{\text {plume }}^{\text {atm }}(\lambda)=S^{\text {atm }}(\lambda)+\Delta S_{\text {plume }}^{\text {atm }}(\lambda)
\end{aligned}
$$

with $\Delta L_{\text {plume }}^{\text {atm }}(\lambda), \Delta E_{\text {plume }}^{\text {surf }}(\lambda), \Delta T_{\text {plume }}^{\text {atm }}(\lambda)$ and $\Delta S_{\text {plume }}^{\text {atm }}(\lambda)$, respectively the upwelling atmospheric radiance differential, the total downwelling irradiance differential, the upward transmittance differential and the spherical albedo of the atmosphere differential, between situations with and without the aerosol plume.

When $\rho_{\text {soil }}(\lambda) S^{\text {atm }}(\lambda) \ll 1$ (corresponding to a low natural aerosol load and/or to a small reflectance value) and $\rho_{\text {soil }}(\lambda) S_{\text {plume }}^{\text {atm }}(\lambda) \ll 1$ (corresponding to a low aerosol plume abundance and/or to a small reflectance value), the at-sensor radiance differential $\Delta L_{\text {plume }}^{\text {sensor }}(\lambda)$ is obtained by subtracting (2) from (3) and is written as

$$
\begin{aligned}
\Delta L_{\text {plume }}^{\text {sensor }}(\lambda)= & \Delta L_{\text {plume }}^{\text {atm }}(\lambda) \\
& +\frac{\rho_{\text {soil }}(\lambda)}{\pi}\left(\Delta E_{\text {plume }}^{\text {surf }}(\lambda) T^{\text {atm }}(\lambda)+E^{\text {surf }}(\lambda) \Delta T_{\text {plume }}^{\text {atm }}(\lambda)+\Delta E_{\text {plume }}^{\text {surf }}(\lambda) \Delta T_{\text {plume }}^{\text {atm }}(\lambda)\right)
\end{aligned}
$$

$\Delta L_{\text {plume }}^{\text {sensor }}(\lambda)$ is assumed to be linear in terms of optical thickness (see discussion in paragraph 3.1.2). This differential radiative term at a particular AOT, named the 'reference AOT' $\tau_{\text {ref }}^{550}$ (more details about it are discussed in paragraph 3.2.2), is also considered to be known, then its value for another optical thickness $\tau^{550}$ can be retrieved by using a factorization along the optical thicknesses ratio $\frac{\tau^{550}}{\tau_{\text {ref }}^{550}}$. It can be expressed under the form $\Delta L_{\text {plume }}^{\text {sensor }}\left(\lambda, \tau^{550}\right)=\frac{\tau^{550}}{\tau_{\text {ref }}^{550}} \Delta L_{\text {plume }}^{\text {sensor }}\left(\lambda, \tau_{\text {ref }}^{550}\right)$, which is written in developed form as

$$
\begin{aligned}
\Delta L_{\text {plume }}^{\text {sensor }}\left(\lambda, \tau^{550}\right)= & \frac{\tau^{550}}{\tau_{\text {ref }}^{550}}\left[\Delta L_{\text {plume }}^{\text {atm }}\left(\lambda, \tau_{\text {ref }}^{550}\right)+\frac{\rho_{\text {soil }}(\lambda)}{\pi}\left(\Delta E_{\text {plume }}^{\text {surf }}\left(\lambda, \tau_{\text {ref }}^{550}\right) T^{\text {atm }}(\lambda)+E^{\text {surf }}(\lambda)\right.\right. \\
& \left.\left.\Delta T_{\text {plume }}^{\text {atm }}\left(\lambda, \tau_{\text {ref }}^{550}\right)+\Delta E_{\text {plume }}^{\text {surf }}\left(\lambda, \tau_{\text {ref }}^{550}\right) \Delta T_{\text {plume }}^{\text {atm }}\left(\lambda, \tau_{\text {ref }}^{550}\right)\right)\right]
\end{aligned}
$$

$\Delta L_{\text {plume }}^{\text {sensor }}\left(\lambda, \tau^{550}\right)$ is thereby written in equation (9) as the product of two terms, which are, respectively, a concentration ratio $a\left(\tau^{550}\right)=\frac{\tau^{550}}{\tau_{\text {ref }}^{550}}$ and $b(\lambda)$ a characteristic spectral signature for the aerosol, depending on differential radiative terms and ground reflectance, written as 


$$
\begin{aligned}
b(\lambda)= & \Delta L_{\text {plume }}^{\text {atm }}\left(\lambda, \tau_{\text {ref }}^{550}\right) \\
& +\frac{\rho_{\text {soil }}(\lambda)}{\pi}\left(\Delta E_{\text {plume }}^{\text {surf }}\left(\lambda, \tau_{\text {ref }}^{550}\right) T^{\text {atm }}(\lambda)+E^{\text {surf }}(\lambda) \Delta T_{\text {plume }}^{\text {atm }}\left(\lambda, \tau_{\text {ref }}^{550}\right)+\Delta E_{\text {plume }}^{\text {surf }}\left(\lambda, \tau_{\text {ref }}^{550}\right) \Delta T_{\text {plume }}^{\text {atm }}\left(\lambda, \tau_{\text {ref }}^{550}\right)\right)
\end{aligned}
$$

The at-sensor radiance differential is thereby linear in $\tau^{550}$ and thus is adapted to the CTMF formulation (see paragraph 4.4.2).

\subsection{Model validation}

Two aspects of the model presented above must be validated thereafter. Firstly, we want to ensure the quality of the modelling of the spectral shape of the total differential radiance $\Delta L_{\text {plume }}^{\text {sensor }}\left(\lambda, \tau^{550}\right)$ that could be measured at the sensor (paragraph 3.2.1). Secondly, the range of validity of the model around a chosen reference optical thickness $\tau_{\text {ref }}^{550}$ should be studied (paragraph 3.2.2). These validations are conducted here using AVIRIS spectral characteristics as a reference, in order to analyse a complete spectra between 0.4 and $2.5 \mu \mathrm{m}$. MODTRAN inputs (Kneizys et al. 1996) are given in Table 2.

\subsubsection{At-sensor spectral radiance}

The purpose of this section is to validate the differential model defined by equation (9) by computing the following radiative terms with MODTRAN: $L^{\text {sensor }}(\lambda), L_{\text {plume }}^{\text {sensor }}(\lambda), L^{\text {atm }}(\lambda)$, $E^{\text {surf }}(\lambda), T^{\text {atm }}(\lambda), L_{\text {plume }}^{\text {atm }}(\lambda), E_{\text {plume }}^{\text {surf }}(\lambda)$ and $T_{\text {plume }}^{\text {atm }}(\lambda)$. The first two terms are taken as reference for 'real' at-sensor differential radiance, referred as $\Delta L_{\mathrm{MDT}}(\lambda)$. The last six terms are used within equation (10) to compute the modelled at-sensor radiance differential, written in this paragraph $\Delta L_{\text {model }}(\lambda)$, for the ten aerosol classes, three reference AOT and three different types of ground detailed below.

Figure 2 is divided into two columns, for the absorbing aerosol accumulation mode on the left and for the scattering one on the right. Figure 2(a,e) compare, for $\tau_{\text {ref }}^{550}=0.25$, the shapes of $\Delta L_{\text {MDT }}(\lambda)$ and $\Delta L_{\text {model }}(\lambda)$ over the range $[0.4 ; 2.5] \mu \mathrm{m}$ for three different grounds. $\rho_{\text {soil }}(\lambda)$ values were chosen from a constant and bright one $\left(\rho_{\text {soil }}(\lambda)=0.1\right)$, water and green vegetation. Figure $2(b, d, f, h)$ present, respectively, for the absorbing and scattering families, the term $\Delta L_{\mathrm{MDT}}(\lambda)-\Delta L_{\text {model }}(\lambda)$, which represents the residue between the MODTRAN reference at-sensor differential radiance and the one computed with the model, over the range $[0.4 ; 1.5] \mu \mathrm{m}$, because residues are zero beyond. Each couple of figures corresponds to a specific ground (2(b) and 2(f) for water, 2(c) and 2(g) for $\rho_{\text {soil }}(\lambda)=0.1$, and $2(\mathrm{~d})$ and $2(\mathrm{~h})$ for vegetation).

Table 2. Parameters used in MODTRAN simulations.

\begin{tabular}{ll}
\hline Sensor altitude $(\mathrm{km})$ & 2 \\
View azimuth and zenith angles $\left(^{\circ}\right)$ & 0 (nadir) \\
Solar zenith angle $\left(^{\circ}\right)$ & 20 \\
Atmospheric model & Mid-Latitude Summer \\
Mean water vapour content $\left(\mathrm{g} \mathrm{cm}^{-2}\right)$ & 1.68 \\
Background aerosols model & Urban \\
Plume's theoretical extent altitudes $(\mathrm{m})$ & 20 to 90 \\
\hline
\end{tabular}


(a)

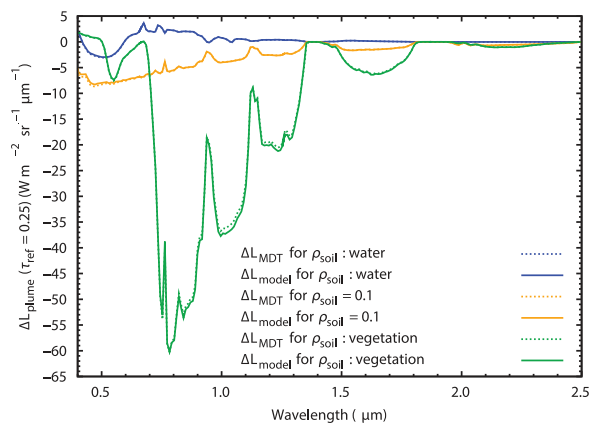

(b)

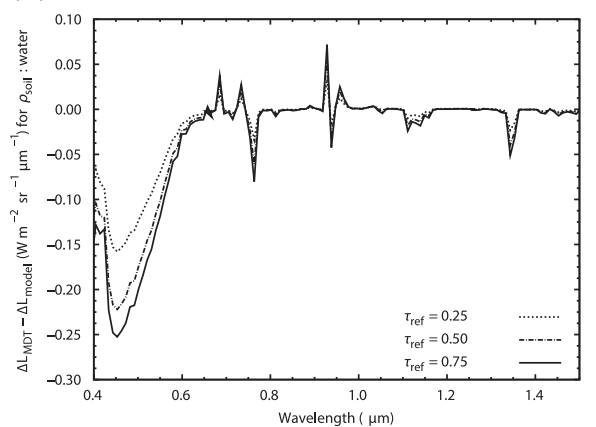

(c)

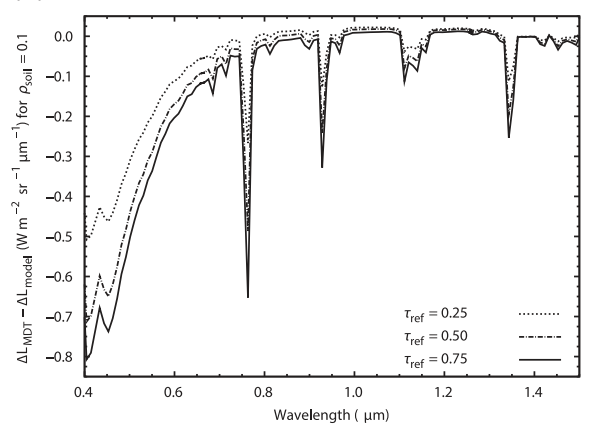

(d)

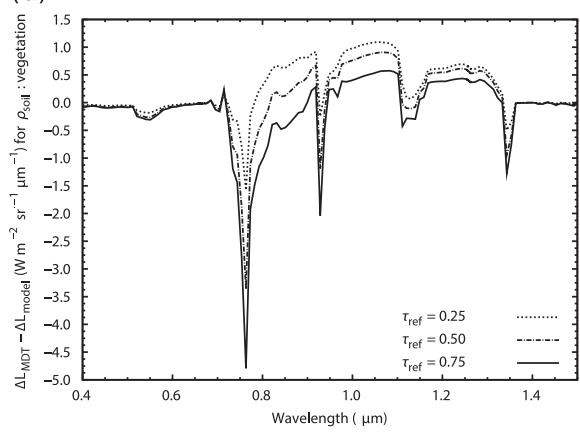

(e)

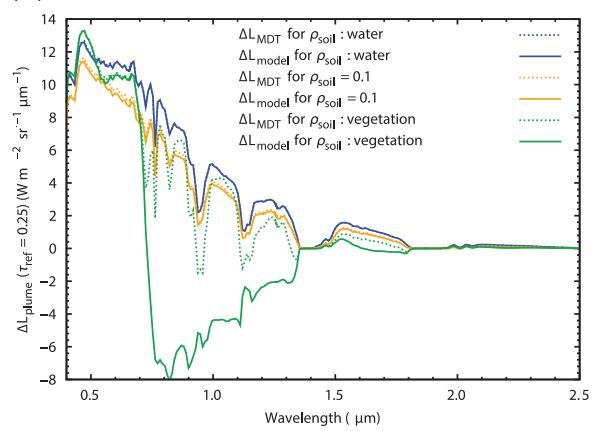

(f)

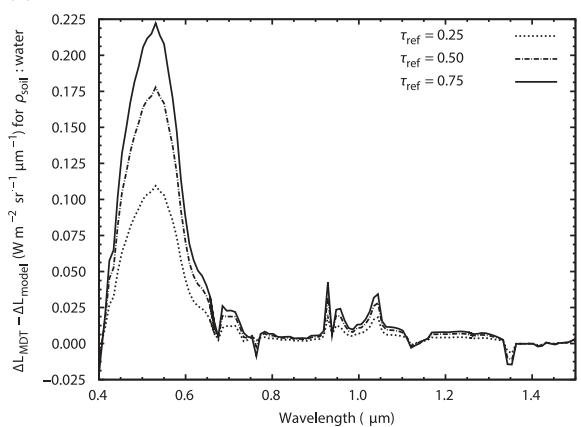

(g)

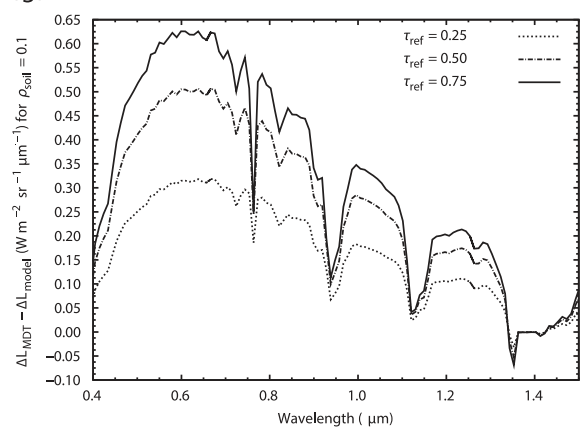

(h)

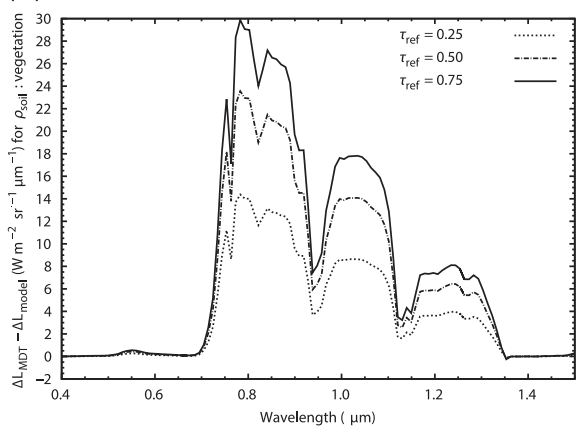

Figure 2. Spectral comparisons of accumulation modes of, on the left, absorbing aerosols and, on the right, scattering aerosols: (a), (e) shapes of $\Delta L_{M D T}$ and $\Delta L_{\text {model }}$ for $\tau^{550}=0.25$ over three grounds, (b), ( $\mathrm{f}$ ) residues for three AOT $(0.25,0.50$, and 0.75$)$ over water, (c), (g) same residues over $\rho_{\text {soil }}(\lambda)=0.1,(\mathrm{~d})$, (h) same residues over vegetation. 
Concerning absorbing aerosols (Figure 2(a)), the highest differences (Figure 2(b,d)) are located in gas absorption bands, especially around $762 \mathrm{~nm}$ for dioxygen $\left(\mathrm{O}_{2}\right)$ and $940 \mathrm{~nm}$ for $\mathrm{H}_{2} \mathrm{O}$. Except for water, they are equivalent or greater than the error due to the aerosol impact (before $750 \mathrm{~nm}$ ), which represent an error of about $10 \%$ of the atsensor differential radiance. So, these gas absorption bands will be excluded in the rest of this study. Concerning scattering aerosols (Figure 2(e)), the residue is mainly located over the spectral region impacted by aerosols over water (compare Figure $2(b, f)$ ). These differences are magnified because of the brightness of both the plume and the surface in the near-infrared region after the vegetation red-edge (compare Figure $2(\mathrm{~d}, \mathrm{~h})$ ). We observe that the gap is produced by the combined effect of, on the one hand, the error made by neglecting multiple scattering between ground and atmosphere (assuming that $\rho_{\text {soil }}(\lambda) S^{\text {atm }}(\lambda) \ll 1$ and $\left.\rho_{\text {soil }}(\lambda) S_{\text {plume }}^{\text {atm }}(\lambda) \ll 1\right)$, and on the other hand, the high values of the ground reflectance (especially between 700 and $1350 \mathrm{~nm}$, where it is higher than 0.3 ). The soil with a constant reflectance $\rho_{\text {soil }}(\lambda)=0.1$ shows a mixture of these two effects (Figure 2(c,g)). This demonstrates the difficulty we could meet for the evaluation of the impact of a scattering plume over a bright ground. With a $10 \%$ maximal overall error on the simulated spectral shape, for all considered optical thicknesses, outside gas absorption bands, the model has higher performances over dark grounds.

The quality of the modelling is evaluated with the Spectral Angle Mapper (SAM) from Kruse et al. (1993). It quantifies the similarity between two spectral vectors, expressed in radian. The lower the SAM angle value is, the more similar the two spectra are. It was applied between $\Delta L_{\mathrm{MDT}}(\lambda)$ and $\Delta L_{\text {model }}(\lambda)$ vectors for three different optical thicknesses $(0.25,0.5$ and 0.75$)$ to ensure the validity of the modelling over a wide range of AOT.

Table 3. Summary of SAM (rounded at $10^{-3}$ ) applied between $\Delta L_{\text {MDT }}$ and $\Delta L_{\text {model }}$ for the ten aerosol classes over ground reflectance at 0.1 , vegetation ('Veg') and water on $[0.4 ; 1.5] \mu \mathrm{m}$ outside gas absorption bands (in bold: outstanding values discussed in the text).

\begin{tabular}{|c|c|c|c|c|c|c|c|c|c|}
\hline \multirow{2}{*}{$\begin{array}{l}\text { Aerosol } \\
\text { classes }\end{array}$} & \multicolumn{3}{|c|}{$\tau_{\text {ref }}^{550}=0.25$} & \multicolumn{3}{|c|}{$\tau_{\mathrm{ref}}^{550}=0.5$} & \multicolumn{3}{|c|}{$\tau_{\text {ref }}^{550}=0.75$} \\
\hline & 0.1 & Veg. & Water & 0.1 & Veg. & Water & 0.1 & Veg. & Water \\
\hline $\begin{array}{l}\text { Fine mode } \\
\text { absorbing aerosol }\end{array}$ & 0.022 & 0.009 & 0.019 & 0.017 & 0.008 & 0.016 & 0.014 & 0.007 & 0.014 \\
\hline $\begin{array}{l}\text { Accumulation mode } \\
\text { absorbing aerosol }\end{array}$ & 0.025 & 0.012 & 0.026 & 0.019 & 0.009 & 0.021 & 0.016 & 0.007 & 0.018 \\
\hline $\begin{array}{l}\text { Coarse mode } \\
\text { absorbing aerosol }\end{array}$ & 0.028 & 0.011 & 0.027 & 0.021 & 0.008 & 0.023 & 0.018 & 0.007 & 0.020 \\
\hline $\begin{array}{l}\text { Fine mode } \\
\text { scattering aerosol }\end{array}$ & 0.014 & 0.228 & 0.004 & 0.011 & 0.204 & 0.002 & 0.009 & 0.189 & 0.002 \\
\hline $\begin{array}{l}\text { Accumulation mode } \\
\text { scattering aerosol }\end{array}$ & 0.011 & 0.847 & 0.003 & 0.008 & 0.717 & 0.003 & 0.007 & 0.615 & 0.002 \\
\hline $\begin{array}{l}\text { Coarse mode } \\
\text { scattering aerosol }\end{array}$ & 0.010 & 0.748 & 0.003 & 0.009 & 0.690 & 0.003 & 0.008 & 0.632 & 0.002 \\
\hline $\begin{array}{l}\text { Fine mode } \\
\text { brown carbon }\end{array}$ & 0.043 & 0.321 & 0.005 & 0.031 & 0.312 & 0.004 & 0.024 & 0.306 & 0.003 \\
\hline $\begin{array}{l}\text { Accumulation mode } \\
\text { brown carbon }\end{array}$ & 0.017 & 1.267 & 0.006 & 0.013 & 1.012 & 0.005 & 0.012 & 0.826 & 0.004 \\
\hline $\begin{array}{l}\text { Coarse mode } \\
\text { brown carbon }\end{array}$ & 0.012 & 0.699 & 0.012 & 0.009 & 0.460 & 0.010 & 0.008 & 0.338 & 0.008 \\
\hline Liquid water & 0.006 & 0.487 & 0.002 & 0.006 & 0.502 & 0.002 & 0.006 & 0.507 & 0.002 \\
\hline
\end{tabular}


Results are summarised in Table 3 over the spectral range $[0.4 ; 1.5] \mu \mathrm{m}$. It confirms that the model performances are degraded for bright grounds (as vegetation in the nearinfrared) below a scattering plume. The performances concerning absorbing aerosols are similar over water and $\rho_{\text {soil }}(\lambda)=0.1$, despite higher minimum values than the other classes (especially over water, caused by the lack of signal reaching the sensor due to an absorbing plume over an absorbing ground, and where the signature is closed to 0 ), but on a less extensive range of them (SAM is ranging between 0.014 and $0.028 \mathrm{rad}$ ). The scattering classes take SAM values over water and constant bright soil from 0.002 to 0.014 rad, with higher values for the fine mode. Brown carbon family has globally comparable results, except for its fine mode over the constant reflectance soil (SAM values are between 0.024 and $0.043 \mathrm{rad}$ ). At the same time, SAM values over vegetation are about twenty to hundred times higher than below darker soils such as water, averaging from 0.189 up to 0.847 rad for scattering aerosols, against 0.007 to 0.012 rad for the absorbing ones. Brown carbon classes get the poorer results (from 0.306 to $1.267 \mathrm{rad}$ ). It is an unavoidable uncertainty related to the impossibility of writing an exact analytical model of scattering and the effect of neglecting the aerosol plume impact on the spherical albedo of the atmosphere $S_{\text {plume }}^{\text {atm }}(\lambda)$, related to the high reflectance value of the ground on a large part of the spectra.

It is important to note that, over vegetation, if the spectral range used to compute SAM is restricted to $[0.4 ; 0.7] \mu \mathrm{m}$ (before the red-edge, with a soil reflectance lower than 0.3 ), the values for every class become close to other grounds (as summarized in Table 4). SAM values for absorbing classes (and the three grounds) are between 0.007 and $0.035 \mathrm{rad}$, those for scattering classes are between 0.002 and $0.013 \mathrm{rad}$ and those for brown carbon are between 0.003 and 0.041 . Concerning liquid water, SAM values are not modified, except over vegetation where they decreased to 0.004 .

Table 4. Summary of SAM (rounded at $10^{-3}$ ) applied between $\Delta L_{\text {MDT }}$ and $\Delta L_{\text {model }}$ for the ten aerosol classes over ground reflectance at 0.1 , vegetation ('Veg') and water on [0.4;0.7] $\mu \mathrm{m}$ (in bold: outstanding values discussed in the text).

\begin{tabular}{|c|c|c|c|c|c|c|c|c|c|}
\hline \multirow{2}{*}{$\begin{array}{l}\text { Aerosol } \\
\text { classes }\end{array}$} & \multicolumn{3}{|c|}{$\tau_{\text {ref }}^{550}=0.25$} & \multicolumn{3}{|c|}{$\tau_{\mathrm{ref}}^{550}=0.5$} & \multicolumn{3}{|c|}{$\tau_{\text {ref }}^{550}=0.75$} \\
\hline & 0.1 & Veg. & Water & 0.1 & Veg. & Water & 0.1 & Veg. & Water \\
\hline $\begin{array}{l}\text { Fine mode } \\
\text { absorbing aerosol }\end{array}$ & 0.021 & 0.010 & 0.019 & 0.016 & 0.008 & 0.015 & 0.014 & 0.007 & 0.014 \\
\hline $\begin{array}{l}\text { Accumulation mode } \\
\text { absorbing aerosol }\end{array}$ & 0.024 & 0.016 & 0.030 & 0.018 & 0.012 & 0.023 & 0.015 & 0.010 & 0.019 \\
\hline $\begin{array}{l}\text { Coarse mode } \\
\text { absorbing aerosol }\end{array}$ & 0.026 & 0.021 & 0.035 & 0.020 & 0.015 & 0.028 & 0.017 & 0.012 & 0.023 \\
\hline $\begin{array}{l}\text { Fine mode } \\
\text { scattering aerosol }\end{array}$ & 0.013 & 0.007 & 0.004 & 0.009 & 0.005 & 0.002 & 0.008 & 0.004 & 0.002 \\
\hline $\begin{array}{l}\text { Accumulation mode } \\
\text { scattering aerosol }\end{array}$ & 0.009 & 0.007 & 0.003 & 0.007 & 0.006 & 0.003 & 0.006 & 0.005 & 0.002 \\
\hline $\begin{array}{l}\text { Coarse mode } \\
\text { scattering aerosol }\end{array}$ & 0.007 & 0.006 & 0.003 & 0.007 & 0.006 & 0.002 & 0.006 & 0.005 & 0.002 \\
\hline $\begin{array}{l}\text { Fine mode } \\
\text { brown carbon }\end{array}$ & 0.041 & 0.009 & 0.005 & 0.029 & 0.007 & 0.004 & 0.023 & 0.005 & 0.003 \\
\hline $\begin{array}{l}\text { Accumulation mode } \\
\text { brown carbon }\end{array}$ & 0.023 & 0.008 & 0.008 & 0.019 & 0.006 & 0.007 & 0.017 & 0.005 & 0.006 \\
\hline $\begin{array}{l}\text { Coarse mode } \\
\text { brown carbon }\end{array}$ & 0.013 & 0.017 & 0.020 & 0.011 & 0.016 & 0.017 & 0.010 & 0.015 & 0.015 \\
\hline Liquid water & 0.005 & 0.004 & 0.002 & 0.005 & 0.004 & 0.002 & 0.005 & 0.004 & 0.002 \\
\hline
\end{tabular}


It highlights the performances of the model to reproduce the spectral shapes of the signal even for dark surfaces and absorbing aerosols. The brown carbon family behaves in a worse way to the scattering family, combining absorbing and scattering errors along the spectra. This leads to pay more attention for dark grounds in order to study CTMF results for aerosol detection, outside gas absorption bands.

\subsubsection{Reference optical thickness and range of validity}

We have seen in the previous section that the model can reproduce the spectral shape of the at-sensor radiance with an aerosol plume under certain conditions: outside of gas absorption bands and high ground reflectance. Here, we are interested in retrieving the AOT by the linear model.

The modelling assumption introducing the 'reference optical thickness' consists in the linearity of the differential radiative term $\Delta L_{\text {plume }}^{\text {sensor }}(\lambda)$ from equation (10), in terms of optical thickness, over a neighbourhood of $\tau_{\text {ref }}^{550}$, the chosen reference AOT at $550 \mathrm{~nm}$. In order to demonstrate the validity of this assumption and to evaluate the amplitude of this neighbourhood, we perform MODTRAN simulations achieved for each aerosol class and six different optical thicknesses $(0.1,0.2,0.3,0.4,0.5$, and 0.6$)$, plus a situation without plume and another for reference AOT fixed at 0.25 , for the same three different grounds $\left(\rho_{\text {soil }}(\lambda)=0.1\right.$, water and green vegetation). Simulation conditions for MODTRAN inputs are the same than previously (listed in Table 2).

Figure 3 is obtained by expressing $\tau^{550}$ from equation (9), for the three types of soils and the ten aerosol classes. We suppose here that $\Delta L_{\text {plume }}^{\text {sensor }}\left(\lambda, \tau^{550}\right), \tau_{\text {ref }}^{550}$ and $b(\lambda)$ are known and thus we can evaluate the performances of the model. We display on the figure the value computed at $550 \mathrm{~nm}$.

Over dark surfaces such as water (Figure 3(a)), plumes of fine mode absorbing aerosol and coarse mode brown carbon are the most unfavourable situations, presenting the largest differences between simulated and estimated AOT. They, respectively, correspond to a maximum error margin of $9 \%$ for $\tau^{550}=0.4$ (retrieved AOT is 0.36 ) and $11 \%$ for $\tau^{550}=0.3$ (retrieved AOT is 0.26 ). The coarse mode brown carbon is a particular case with a saturation phenomena for $\tau_{\text {ref }}^{550} \geq 0.5$. All classes underestimate the plume AOT, except the fine mode brown carbon and the fine mode scattering aerosols. The latter has the higher overestimated error equal to $11 \%$ at $\tau^{550}=0.5$ (retrieved AOT is 0.55). In comparison, when the AOT of the plume is lower than the reference AOT, for example, with $\tau^{550}=0.1$, fine mode scattering aerosols has an error of about $9 \%$ (retrieved AOT is 0.09); for fine mode absorbing aerosols the error reaches $14 \%$ (retrieved AOT is about 0.11 ), and it is worth than $30 \%$ for coarse mode brown carbon (retrieved AOT is 0.13).

Over brighter surfaces (Figure 3(b)), the range of validity for absorbing aerosols remains the same with a decreasing error for the ten classes. The class that underestimates the most the AOT is the fine mode absorbing aerosols with an error reaching $9 \%$ for $\tau^{550}=0.4$ (retrieved AOT is 0.36 ). The class that overestimates the most the optical thickness is the fine mode scattering aerosol, with an error of $11 \%$ for $\tau^{550}=0.4$ (for a retrieved AOT of 0.45 ). For an observed plume with $\tau^{550}=0.1$, the error is, respectively, $13 \%$ for fine mode absorbing aerosols (retrieved AOT is 0.11 ) and $8 \%$ for fine mode scattering ones (retrieved AOT is 0.09). 
(a)

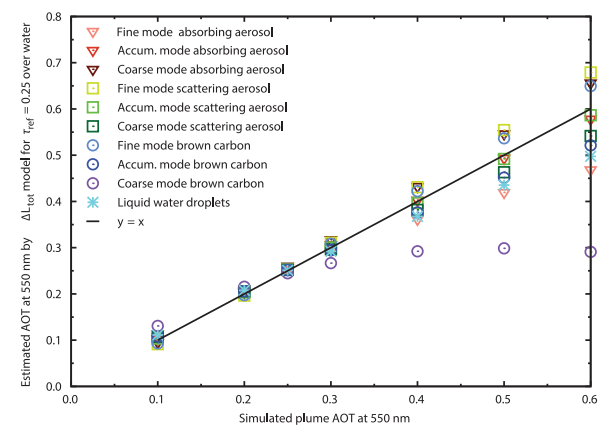

(b)

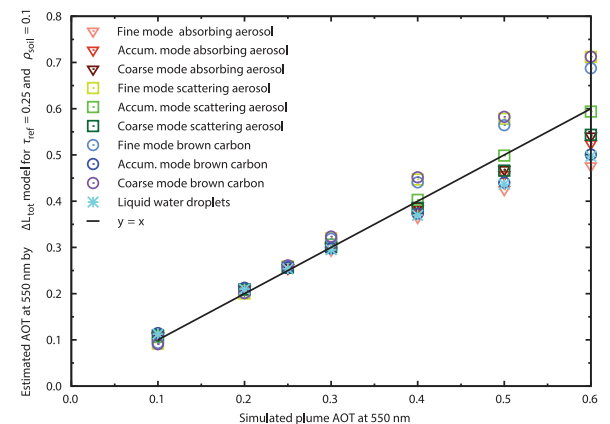

(c)

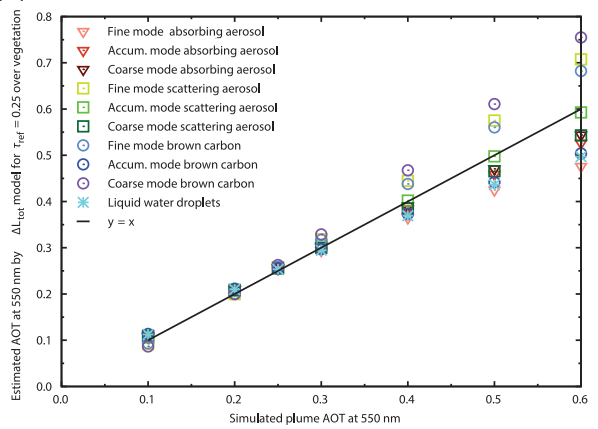

(d)

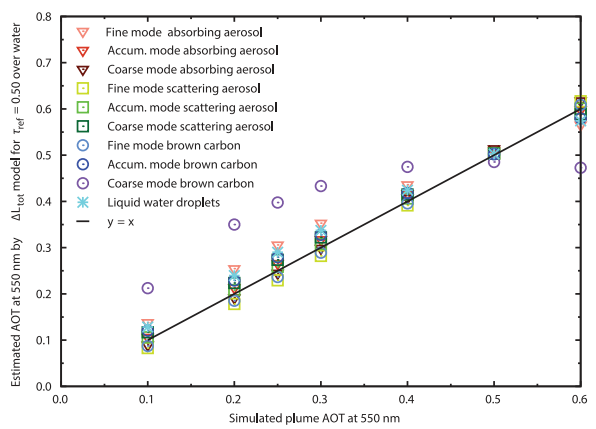

(e)

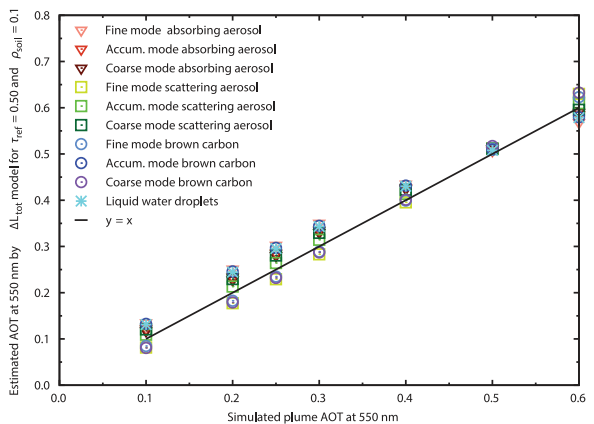

(f)

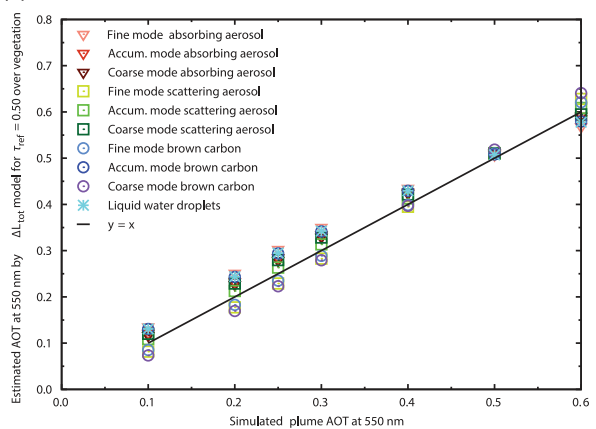

Figure 3. Model performances of the AOT at $550 \mathrm{~nm}$ from the model with $\tau_{\text {ref }}^{550}=0.25$ for left column and $\tau_{\text {ref }}^{550}=0.50$ for right column, with the ten aerosol classes over (a), (d) water, (b), (e) soil with constant reflectance equal to 0.1 , (c), (f) green vegetation.

Over vegetation, if the ground reflectance becomes higher than 0.3 after $700 \mathrm{~nm}$ leading to a poor fit between simulated and MODTRAN radiances, as shown in Figure 2 $(d, h)$, it is not the case at $550 \mathrm{~nm}$ where it only reaches 0.04 . So, AOT retrieval performances are similar to those for water (for which $\rho_{\text {soil }}(\lambda=550 \mathrm{~nm})=0.06$ ). Fine mode absorbing aerosols is again the class that underestimates the most the retrieved AOT, with errors reaching $13 \%$ for $\tau^{550}=0.1$ (retrieved AOT is 0.11 ) and $8 \%$ for $\tau^{550}=$ 0.4 (retrieved AOT is 0.36). The values for the class that overestimates the most the AOT, this time the coarse mode brown carbon, are, respectively, from $13 \%$ (retrieved AOT of 0.09 ) to $17 \%$ (retrieved AOT is 0.47 ). 
Figure $3(d, f)$ show the same behaviours for each soil with $\tau_{\text {ref }}^{550}=0.5$. Better performances are obtained for higher observed AOT (between 0.4 and 0.6 ) but they remain lower than the previous ones if $\tau_{\text {ref }}^{550}=0.25$ and $\tau^{550}<0.4$.

The higher the AOT is, the lower the linearity range becomes and the higher the error is, but we are only interested in thin optical thickness plumes (lower than 0.5). The practical cases studied in this paper (see sections 5 and 6) thus correspond to situations where the linearity range of the model is the most favourable. In a same way, a higher ground reflectance leads to a failure of the hypothesis $\rho_{\text {soil }}(\lambda) S_{\text {plume }}^{\text {atm }}(\lambda) \ll 1$ and therefore to an error on the estimated optical thickness, as seen below.

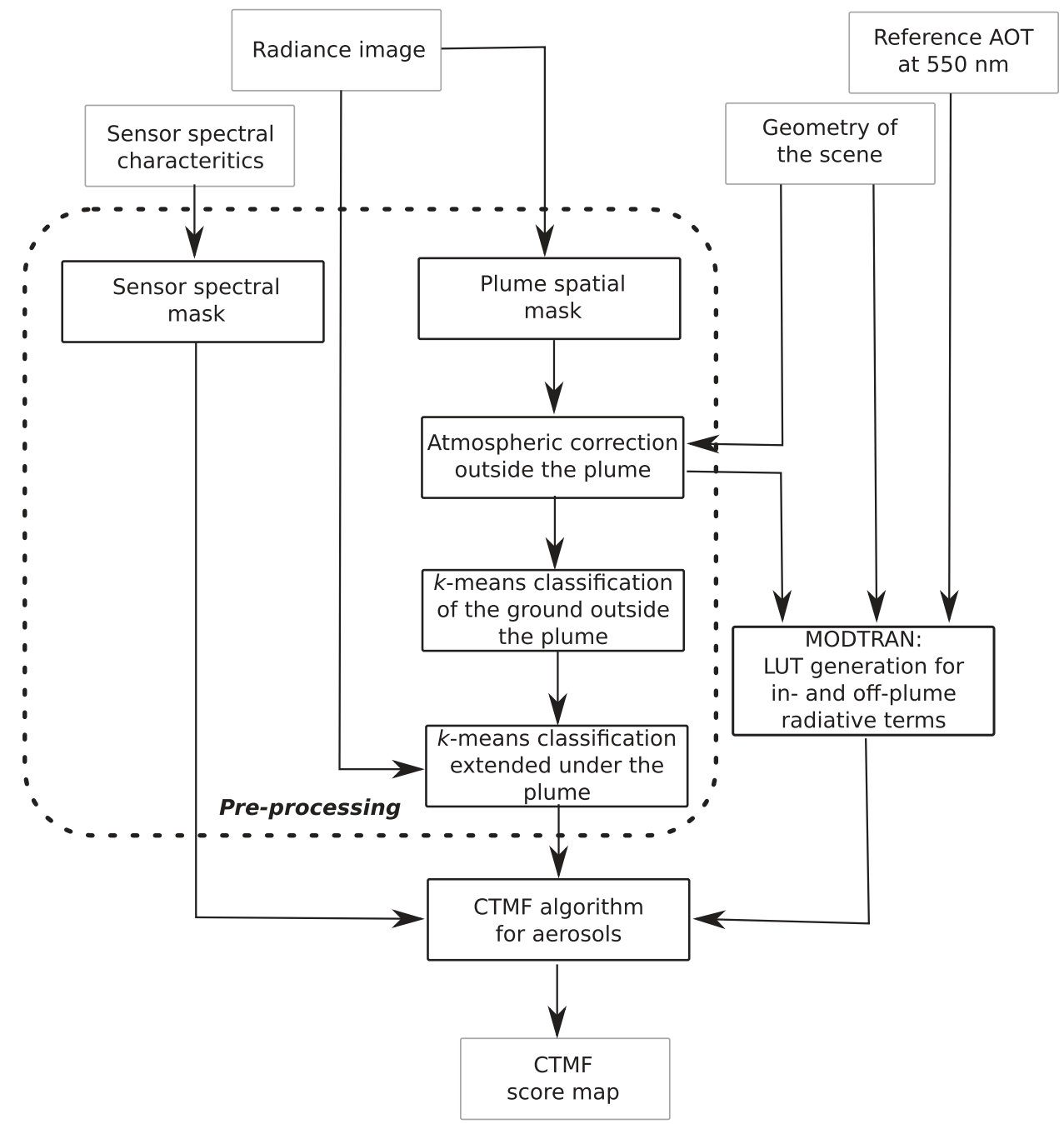

Figure 4. Flowchart of the proposed CTMF-aerosol method for aerosol detection and identification. 
As a conclusion, we can say that for a large variety of soils and for the ten aerosol classes, the model is valid with $\tau_{\text {ref }}^{550}=0.25$ for plumes with AOT ranging between 0.1 and 0.4 with a maximum error of $17 \%$. Globally, this percentage error is higher if the AOT of the plume is below $\tau_{\text {ref }}^{550}$ but the absolute value is lower than the one for observed plumes with AOT greater than $\tau_{\text {ref }}^{550}$. The applications developed later in this paper over industrial sites in sections 5 and 6 are precisely carried out over water.

Now validated for a sufficiently large number of realistic situations, the model is used in the detection and identification method described hereafter.

\section{Detection and identification of aerosol plumes: inverse method description}

\subsection{Overview of the processing scheme}

Figure 4 shows the processing flowchart to build an aerosol detection map. Three main steps can be distinguished and are detailed in the following. First, a pre-processing step is needed to generate a spectral mask, keeping only sensor channels located outside gas absorption bands (paragraph 4.2.1), and a spatial mask of the plume location (paragraph 4.2.2). Then, an atmospheric correction of the image is performed outside the plume thanks to the spatial mask (paragraph 4.2.3). The resulting reflectance image is then processed to retrieve the reflectance for the pixels below the plume (paragraph 4.2.4). Second, we compute with MODTRAN the Look-Up Table (LUT) of radiative terms (paragraph 4.3), that will be used to obtain the spectral signatures for the CTMF algorithm (paragraph 4.4).

\subsection{Pre-processing of the image}

\subsubsection{Sensor spectral mask}

Spectral channels inside gas absorption bands or too noisy are manually selected. A spectral mask is then built to keep the other channels. It will be used to apply the CTMF filter on chosen channels to improve its accuracy.

\subsubsection{Plume spatial mask}

Before performing the atmospheric correction, it is necessary to delimit manually, spatially, and roughly the plume's grip so that aerosol contribution does not impact the atmospheric parameters, especially to retrieve the conditions outside the plume (see paragraph 4.2.3). This mask is also used for the propagation of the ground classification under the plume (detailed in paragraph 4.2.4).

\subsubsection{Atmospheric correction outside the plume}

The atmospheric correction is done with FLAASH (Fast-Line-of-sight Atmospheric Analysis of Spectral Hypercubes), from Anderson et al. (2002). It is applied outside the plume with the use of the spatial mask. On the one hand, this allows recovering the atmospheric model, type, and concentration of background aerosols, in order to compute the corresponding radiative terms from geometric and atmospheric conditions considerations. On the other hand, the output of this atmospheric correction is an 
image, outside the plume, expressed in surface reflectance, which is used in the next processing step.

\subsubsection{Clustering of the reflectance image}

A $k$-means clustering (MacQueen 1957) is performed with ENVI (Environment for Visualizing Images) software with a number of ground classes defined by the user and depending on the complexity of the scene. Thorpe et al. (2013) pointed out that the choice of the number of ground classes should not lead to classes with to few pixels to correctly calculate the covariance matrix. It is therefore necessary to limit the number of classes while taking enough classes to represent the complexity of the scene. This clustering takes as input the reflectance image and the spatial mask. The objective is to cluster the scene only outside the plume into a number of classes sufficiently representative of the background overflown by this plume. For each class of soil thereby obtained, the mean soil reflectance value $\rho_{\text {soil }}$ appearing in equation (10) is derived.

\subsubsection{Retrieval of ground reflectance below the plume}

To obtain a complete reflectance image, we need to propagate the existing ground classes below the plume. Alakian et al. (2008) proposed a method based on Bojinski et al. (2002), supposing the plume becomes transparent for wavelengths beyond $1.5 \mu \mathrm{m}$. For each pixel under the plume, its reflectance beyond $1.5 \mu \mathrm{m}$ is compared to reflectance of pixels outside the plume. The nearest value is then assigned to the pixel. Deschamps (2012) adapted this method to CASI (Compact Airborne Spectrographic Imager) images for which the covered spectral domain is between 0.4 and $1.0 \mu \mathrm{m}$. We adapted it, in order to apply this method to several different sensors, and compare the spectrum (with channels which are the less impacted by the plume) of each pixel under the plume to the mean one of each ground class from the $k$-means with a correlation function. The highest score corresponds to the spectrally nearest ground class, and the pixel receives the corresponding mean reflectance.

\subsection{Computation of a LUT-database of radiative properties}

The three differential radiative terms $\Delta L_{\text {plume }}^{\text {atm }}(\lambda), \Delta E_{\text {plume }}^{\text {surf }}(\lambda)$ and $\Delta T_{\text {plume }}^{\text {atm }}(\lambda)$ depend on their 'off-plume' and 'on-plume' radiative components (respectively $L^{\text {atm }}(\lambda)$ and $L_{\text {plume }}^{\text {atm }}(\lambda)$, $E^{\text {surf }}(\lambda)$ and $E_{\text {plume }}^{\text {surf }}(\lambda)$, and $T^{\text {atm }}(\lambda)$ and $\left.T_{\text {plume }}^{\text {atm }}(\lambda)\right)$. These six terms are computed with MODTRAN using the atmospheric parameters obtained from the atmospheric correction step. Geometric parameters and sensor specifications used for the computation are those of the image under study. The three 'on-plume' terms are computed using the reference aerosol optical thickness at $550 \mathrm{~nm} \tau_{\text {ref }}^{550}$. These terms are then used with the ground reflectance classification to compute the aerosol signature as presented in equation (10) as an input of the CTMF detailed below.

\subsection{Cluster-Tuned Matched Filter for the aerosol case}

The CTMF algorithm was introduced by Funk et al. (2001) for detecting sulphur dioxide $\left(\mathrm{SO}_{2}\right)$ in the thermal infrared and then extended for some other gases (Thorpe et al. 
2012; Dennison et al. 2013; Thorpe et al. 2013) in the reflected solar energy domain. Gases can be distinguished thanks to their particular well-known absorption bands. However, for aerosols, the impact on the hyperspectral signal is not spectrally localised as for gases but covers the spectral channels in the visible and near-infrared domains. Furthermore, aerosols can both scatter or absorb the radiation, which implies that their spectral signature $\boldsymbol{b}$ can take, respectively, positive or negative values, unlike gases signatures. The objective of this section is to express this signature in the aerosol case.

Taking as input an image with $N$ pixels and $\boldsymbol{n}$ spectral bands, the CTMF models the atsensor radiance $L_{\text {plume }}^{\text {sensor }}$ (a $n$-dimensional vector) as a linear combination of the background signal $L^{\text {sensor }}$ (also a $n$-dimensional vector) and a certain amount $a$ (scalar) of the target (here the aerosol) described by its spectral signature $\boldsymbol{b}$ ( $n$-dimensional vector). A $k$-means classification is performed on the reflectance image to obtain, for each ground class (indexed by $j$ ), the mean soil reflectance and the background radiance $\boldsymbol{L}_{j}^{\text {sensor }}$ (used in equation 10), and the inverse of the correlation matrix $\mathbf{C}_{j}^{-1}$ (matrix of size $n \times n$ ). The optimal filter $\boldsymbol{q}_{j}$ (a $n$-dimensional vector) for class $j$ is then

$$
\boldsymbol{q}_{j}=\frac{\boldsymbol{C}_{j}^{-1} \boldsymbol{b}}{\sqrt{\boldsymbol{b}^{\top} \boldsymbol{C}_{j}^{-1} \boldsymbol{b}}}
$$

The detection score for pixel $i$ in ground class $j$ is a scalar written as

$$
f_{i, j}=\boldsymbol{q}_{j}^{\top}\left(\boldsymbol{L}_{\text {plume }_{i, j}}^{\text {sensor }}-\boldsymbol{L}_{j}^{\text {sensor }}\right)
$$

A detection map is thus built where, outside the plume, the detection score is averaging 0 with a standard deviation of 1 (theoretical behaviour of CTMF detection score). The more the target is concentrated into the pixel, the greater the score becomes. The following paragraphs describe how this method is adapted to the case of aerosols.

From the model in equation (9), we compute $\Delta L_{\text {plume }_{i, j}}^{\text {sensor }}\left(\tau^{550}\right)$, a $n$-dimensional vector made of $\Delta L_{\text {plume }}^{\text {sensor }}\left(\lambda, \tau^{550}\right)$ values for pixel $i$ in class $j$. Using equation (12), the following form is obtained for the detection score in the aerosol case:

$$
f_{i, j}=\boldsymbol{q}_{j}^{\top} \Delta \boldsymbol{L}_{\text {plume }_{i, j}}^{\text {sensor }}\left(\tau^{550}\right)=a_{i}\left(\tau^{550}\right) \boldsymbol{q}_{j}^{\top} \boldsymbol{b}_{i, j}\left(\tau^{550}\right)
$$

Figure 5 points out the different behaviours of the spectral signatures for the ten aerosol classes, plotted from MODTRAN computations (simulation conditions are given in Table 2). Unlike in the case of gases, the magnitude of these variations for the aerosol signatures depends on the soil according to equation (10). As it can be seen on Figure 5(a,b), with two soils with quasi constant reflectances (the first is water, the second is $\rho_{\text {soil }}(\lambda)=0.1$ ), scattering classes have positive signatures $\boldsymbol{b}$ on the range $[0.4 ; 2.5] \mu \mathrm{m}$, absorbing ones have negative signatures, and brown carbon signatures show its particular absorption behaviour in the ultraviolet and scattering near red and infrared regions. The signatures of liquid water have similar behaviours to those of coarse mode scattering aerosol for each ground. A positive value indicates that the plume increases the signal received at the sensor (it is typically the case with a scattering plume over a dark ground), and conversely a negative value corresponds to a decrease of the radiance compared to the same situation without plume. Figure 5(c) is taken over green vegetation, whose reflectance spectrum is 
(a)

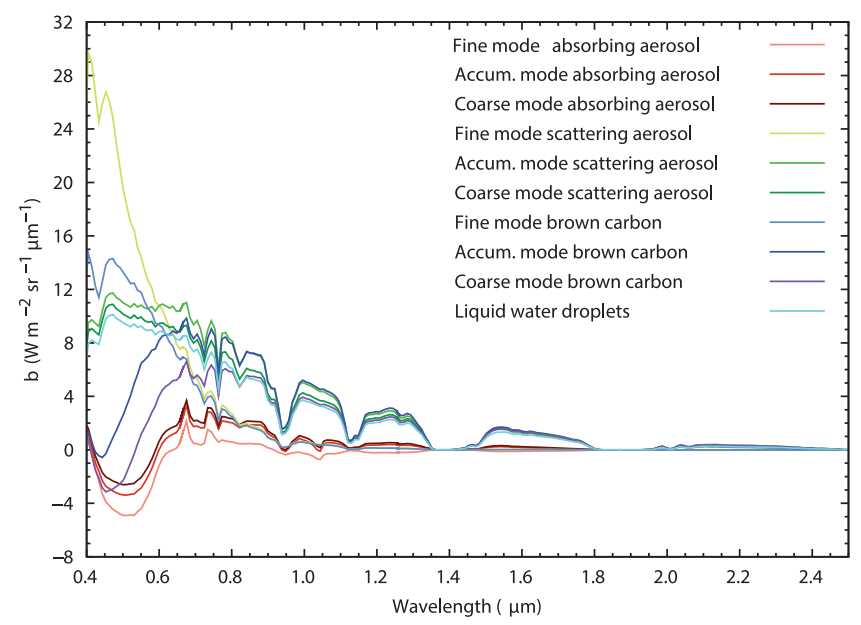

(b)

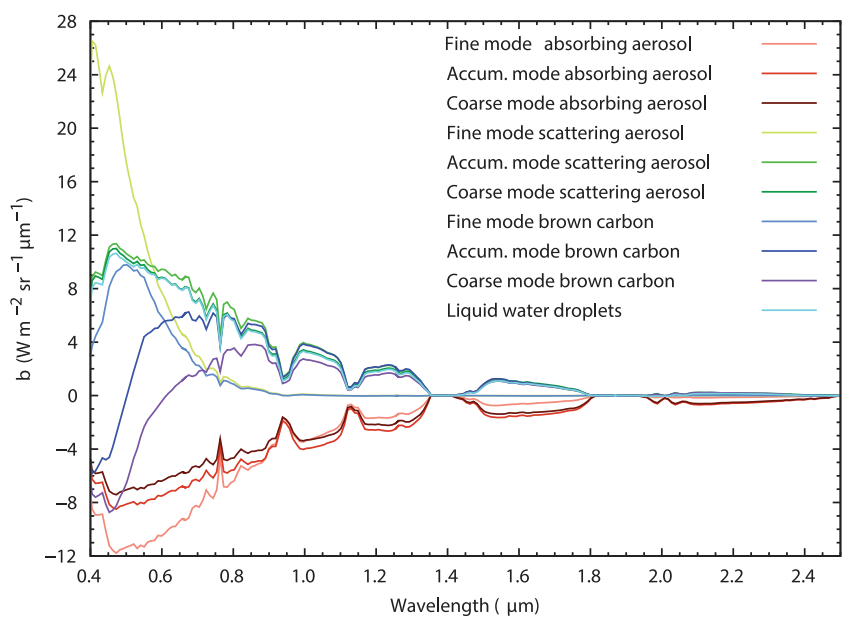

(c)

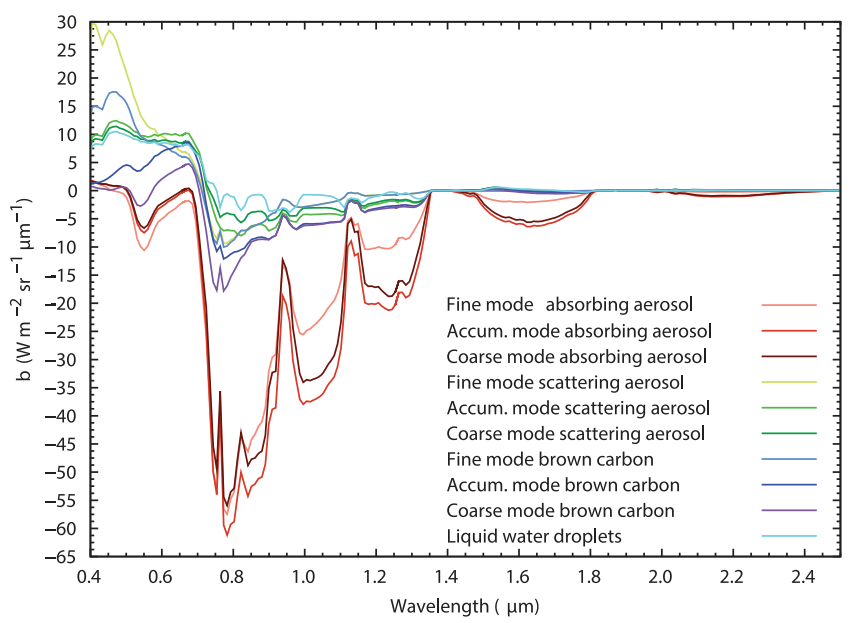

Figure 5. Aerosol signatures $b$ at $\tau_{\text {ref }}^{550}=0.25$ for simulation conditions in Table 2 and AVIRIS spectral characteristics, over three different soils: (a) water, (b) constant reflectance equal to 0.1 , (c) green vegetation. 
dark in the visible and much higher in the near-infrared. This explains that the whole signatures become negative after the red-edge and for the absorbing aerosols even more. As a conclusion, it is clear that some situations cause inevitable confusions and difficulties to distinguish some classes from the same family, as, for example, the absorbing classes over a dark soil (the three corresponding signatures are very similar as shown on Figure 5(a)).

The term $a$ only depends on aerosol optical thickness. It is the ratio of the observed or researched aerosol optical thickness to the reference optical thickness used to

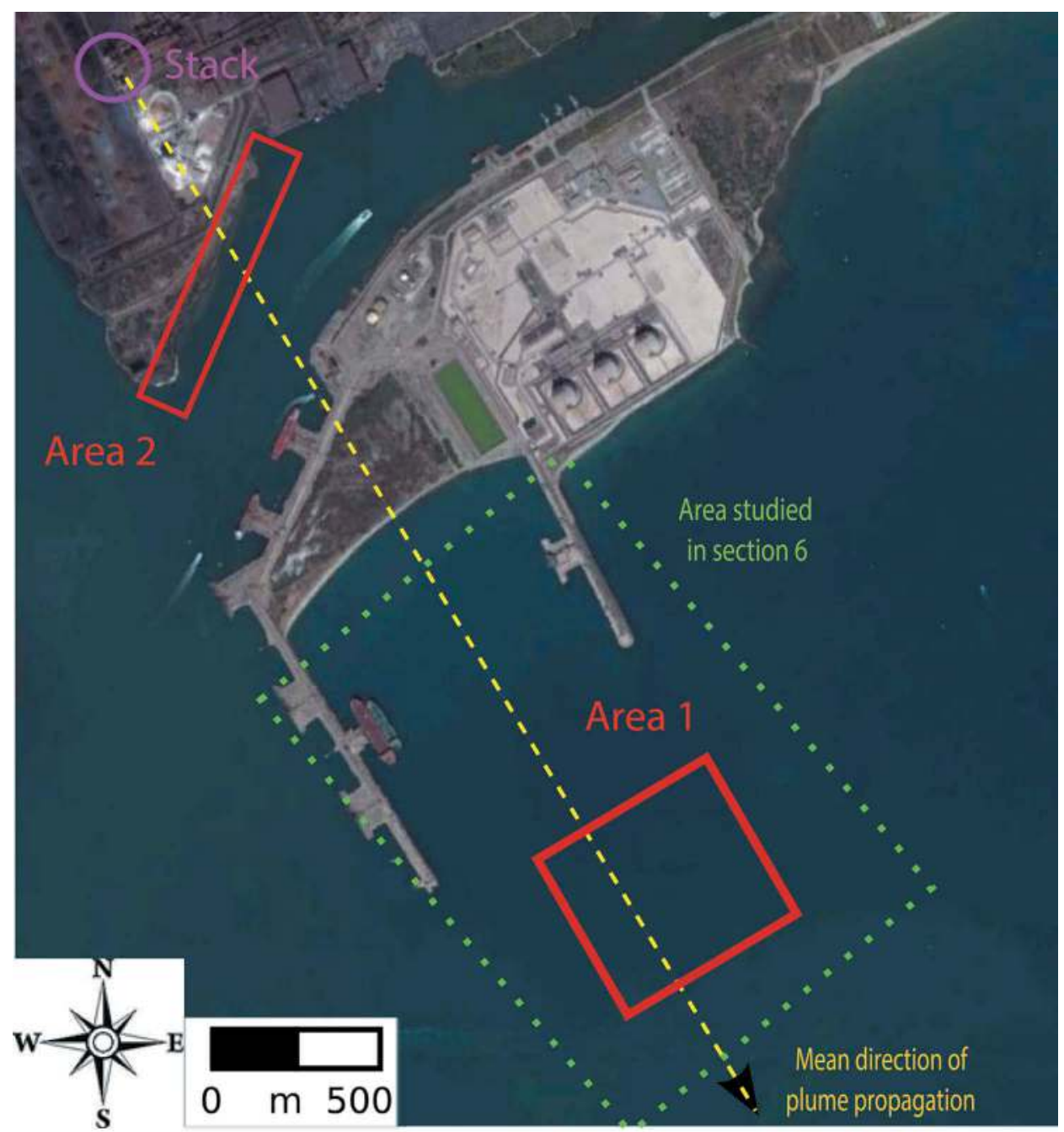

Figure 6. Overview of the ArcelorMittal plant in Fos-sur-Mer (screenshot from Google Earth), with delimitations of the two studied areas. 
compute the radiative terms. The signature $\boldsymbol{b}$ depends on radiative terms from the radiative transfer equation (in and off-plume terms) but also on the ground reflectance (unlike the gas case for CTMF). Consequently, some combinations of aerosols and soil types can lead to the impossibility of detecting the plume, for example, a scattering aerosol plume over clear concrete or an absorbing aerosol plume over water.

In practice, to determine which aerosol is contained into the plume, the number of occurrence of each class is used.

In the following, we apply the CTMF filter to detect and identify aerosol plumes in real hyperspectral images.

\section{Application to real hyperspectral images}

\subsection{CASI images over Fos-sur-Mer, France}

\subsubsection{Data description}

The industrial site of Fos-sur-Mer is located in south-eastern France, near the delta of the Rhône River. The campaign EUFAR (European Facility for Airborne Research) ValCalHyp 2010 offered opportunity to acquire two airborne images the 28 October 2010 from CASI-1500, a Vis/NIR (Visible and Near-Infrared) pushbroom imaging spectrograph with 144 spectral channels from 0.367 to $1.052 \mu \mathrm{m}$. The flight altitude was $1950 \mathrm{~m}$ leading to a spatial resolution of $1.58 \mathrm{~m}$ along track per $0.96 \mathrm{~m}$ across track. This study is focused on the ArcelorMittal plant (see Figure 6), a metallurgical industry which is well known as one of the major French sources of PM10 (Particulate Matter of less than $10 \mu \mathrm{m}$ in diameter), and detailed by Deschamps (2012). During the overflight, the plume was heading southeast direction (represented by the yellow dotted arrow on Figure 6).

Two studied areas were defined. Area 1 (Figure 7(a)), which is a part of the area studied in section 7, contains only water pixels (favourable case with well-known water

(a)

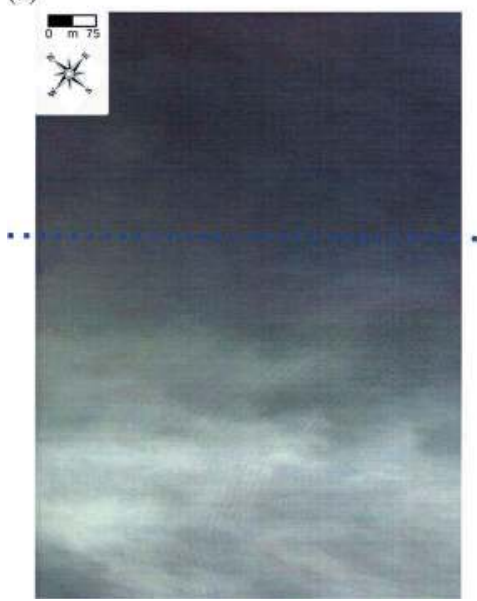

(b)

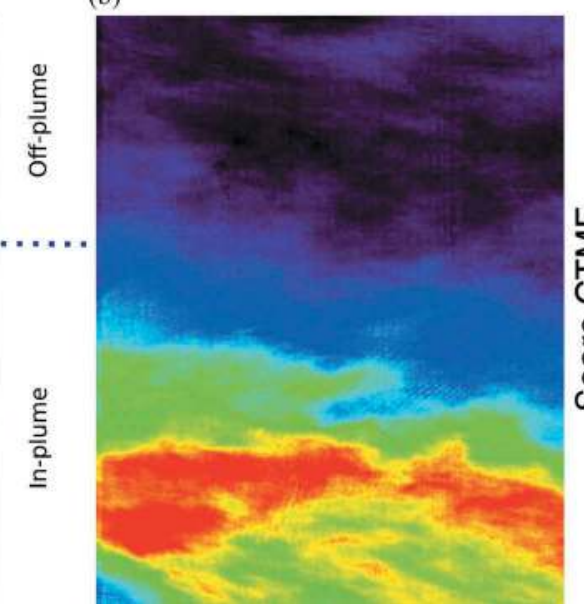

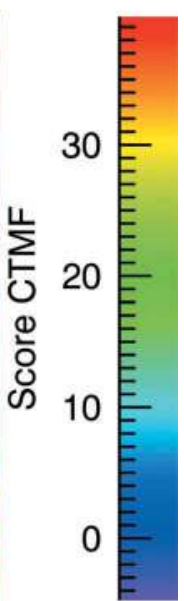

Figure 7. CTMF applied to area 1: (a) RGB composition of the studied area, where the plume (in bright) occupies the bottom of the image; (b) the highest CTMF score for the class of coarse mode scattering aerosol. 
Table 5. Parameters for the CASI images, used for MODTRAN simulations.

\begin{tabular}{ll}
\hline Sensor altitude $(\mathrm{km})$ & 1.95 \\
View azimuth and zenith angles $\left(^{\circ}\right)$ & 0 (nadir) \\
Solar azimuth angle $\left({ }^{\circ}\right)$ & 229.7 \\
Solar zenith angle $\left(^{\circ}\right)$ & $70^{*}$ \\
Atmospheric model & Mid-Latitude Summer \\
Mean water vapour content $\left(\mathrm{g} \mathrm{cm}^{-2}\right)$ & 1.68 \\
Background aerosols model & Urban (visibility: $80 \mathrm{~km}$ ) \\
Plume's theoretical extent altitudes used for simulations $(\mathrm{m})$ & 20 to 90 \\
\hline
\end{tabular}

* The correct value is $71^{\circ}$ but is reduced to $70^{\circ}$ to reach FLAASH specifications.

background reflectance). It is divided into two parts: the first (on the top) is not impacted by the plume (and so-called 'off-plume'); the second (on the bottom) is fully occupied by the plume from the stack (so-called 'in-plume'). Area 2 (Figure 9(a)) is located close to the plant and presents a large variability in terms of soils: water, vegetation, bare soil, and some artificial grounds (unfavourable case).

The LPCA (Laboratoire de Physico-Chimie de l'Atmosphère from Dunkirk, France) provided ground truth data acquired during a 2013 campaign (personal communication). This campaign was not coupled with the EUFAR ValCalHyp one but gives some important information about the different kinds of rejects we could expect from the stack. The main source observed by the LPCA was the sinter plant (whose stack is surrounded in violet on Figure 6), mainly releasing inorganic materials (calcium salts) and aluminosilicate materials, corresponding to scattering families of aerosols from Table 1.

\subsubsection{Atmospheric correction and ground reflectance estimation}

Concerning the area 1 (Figure 7(a)), we divided it into two parts. In the top half of the image (called 'off-plume'), we consider that we are totally outside the plume. So, no ground classification is necessary in this case. Atmospheric correction using geometric parameters of the scene, atmospheric model and background aerosols from Table 5 can be estimated on a lot of pixels here (on the upper part of the image from Figure 7(a)) considering that water above the plume keeps the same characteristics than underneath, and is not suffering from aerosols perturbation. We obtain a mean water vapour content of $1.68 \mathrm{~g} \mathrm{~cm}^{-2}$ and reflectance spectrum of the sea. The mean reflectance spectrum of the sea over pixels outside the plume will be used for the computation of the LUT-database. Considering the spectral mask, only channels 7 to 63 (included) were used for computations inside this area (corresponding to the range $[0.4 ; 0.66] \mu \mathrm{m}$ ). The cut at $0.66 \mu \mathrm{m}$ is explained by the lack of signal received by the sensor above water.

Concerning area 2 (Figure 9(a)), atmospheric correction is performed as the same as for area 1 (results are summarized in Table 5). Then the $k$-means classification is performed to obtain five ground classes and their associated mean reflectance: water, vegetation, bare soil, and artificial surfaces (Figure 9(b)). Considering the spectral mask, only channels 7 to 63 (corresponding to the range $[0.4 ; 0.66] \mu \mathrm{m}$ ) and 78 to 110 (on the range $[0.73 ; 0.89] \mu \mathrm{m}$ ) were used for computations inside this area. The second range is supposed to increase CTMF performances allowing the algorithm to get a part of the 
spectra where aerosols do not impact the signal, so where the ground reflectance and radiance may not be disturbed.

Simulation conditions used for the two CASI images are presented in Table 5 . It is important to note the low solar elevation, that means the MODTRAN hypothesis about an infinite plan parallel plume is not quite respected (direct solar downwelling irradiance may not pass through the plume).

\subsubsection{CTMF application for aerosol properties retrieval above the sea (away from the plant)}

Outside the plume, the mean CTMF scores (Figure 7) for all aerosol classes is on average equal to 0 with standard deviation of 1 , respecting the properties of the filter. These scores for each class taken individually are here slightly biased probably due to spatial mask not covering exactly the whole plume; some artefacts surely remain in pixels used as reference.

Inside the plume, for the ten aerosols classes defined by Table 1, we observe a behaviour of the score that tends to move away from 0 from the sides (negatively for absorbing families, positively for scattering ones) until reaching a threshold value (a maximum in absolute value) at the centre of the plume, near the bottom of the image (Figure $7(b)$ ). Negative values for absorbing aerosol classes indicate that a plume is well detected by the filter but has an opposite spectral behaviour, namely, it is a plume made of scattering particles observed here. No class from the absorbing aerosol family is detected as the most likely in any pixel. From positive values, the highest result on

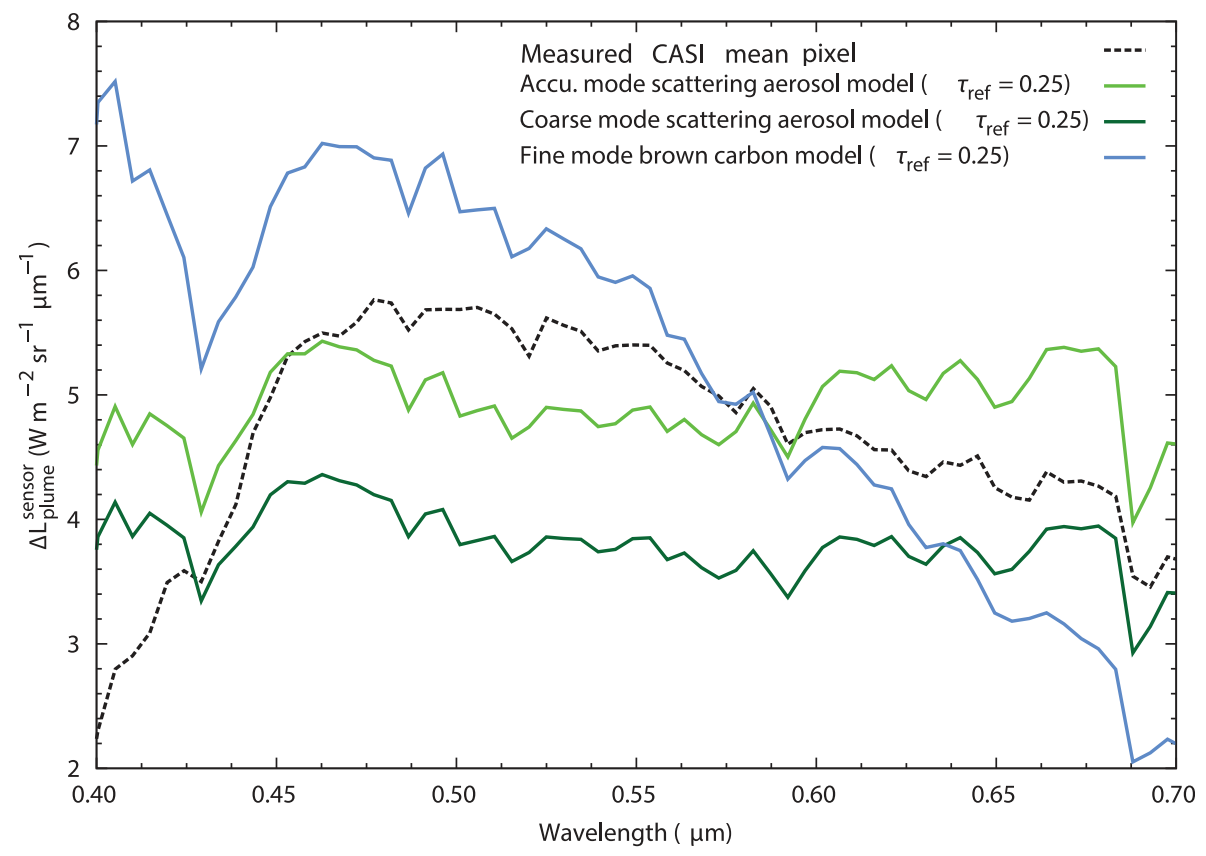

Figure 8. Comparison of the at-sensor radiance differential from accumulation mode scattering aerosol, coarse mode scattering aerosol and fine mode brown carbon computed with our model, and the at-sensor radiance differential between the spectrum collected in the centre of the plume and the one outside on the CASI image (area 1). 
(a)

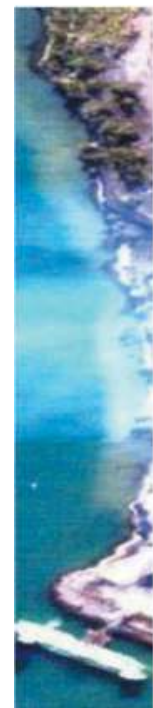

(b)

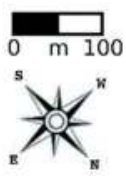

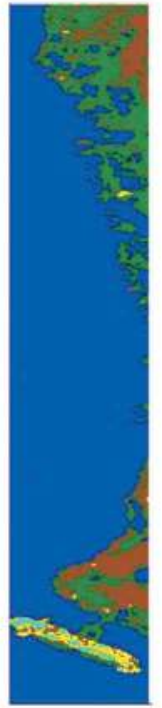

(c)

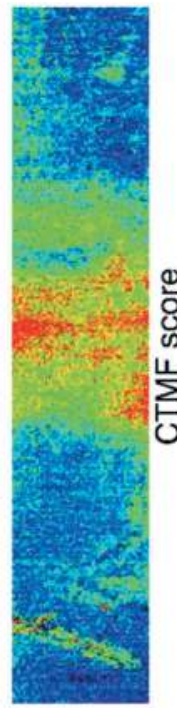

(d)

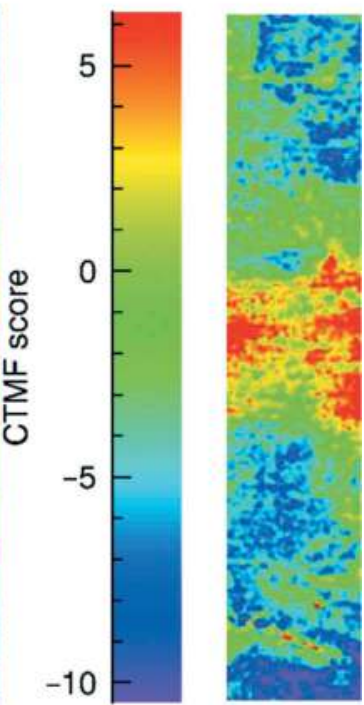

Figure 9. CTMF applied to area 2: (a) RGB composition of the studied area, where the plume (in bright) occupies the centre of the image; (b) $k$-means classification result with 5 ground classes (water in blue, vegetation in green, bare soil in brown, and two types of artificial surfaces in yellow and cyan); (c) one of the highest CTMF scores, here the fine mode scattering aerosol class, (d) CTMF scores of fine mode scattering aerosol after applying low pass $3 \times 3$ filter.

Table 6. CTMF scores in the plume and statistics for the ten aerosol classes on area 1 (in bold: outstanding values discussed in the text).

\begin{tabular}{lccc}
\hline Class & $\begin{array}{c}\text { Mean CTMF score } \\
\text { (standard deviation) }\end{array}$ & $\begin{array}{c}\text { Min and max } \\
\text { CTMF scores }\end{array}$ & $\begin{array}{c}\text { Number of pixels with } \\
\text { the highest score } \\
\text { (value in \%) }\end{array}$ \\
\hline Fine mode & -8.66 & -15.73 & 0 \\
absorbing aerosol & $(1.69)$ & -3.17 & $(0)$ \\
Accumulation mode & -9.56 & -17.60 & 0 \\
absorbing aerosol & $(1.93)$ & -3.90 & $(0)$ \\
Coarse mode & -8.10 & -14.05 & 0 \\
absorbing aerosol & $(1.56)$ & -2.94 & $(0)$ \\
Fine mode & 10.07 & 3.34 & 0 \\
scattering aerosol & $(2.18)$ & 18.98 & $(0)$ \\
Accumulation mode & $\mathbf{2 1 . 8 7}$ & 9.63 & 31,487 \\
scattering aerosol & $(\mathbf{4 . 2 6 )}$ & 51.59 & $\mathbf{( 1 8 . 4 3 )}$ \\
Coarse mode & $\mathbf{2 1 . 9 1}$ & 9.66 & 118,290 \\
scattering aerosol & $\mathbf{( 4 . 2 6 )}$ & 51.42 & $\mathbf{( 6 9 . 2 3 )}$ \\
Fine mode & 21.23 & 9.96 & 19,734 \\
brown carbon & $(4.01)$ & 47.14 & $(11.55)$ \\
Accumulation mode & 17.65 & 7.67 & 0 \\
brown carbon & $(3.38)$ & 44.64 & $(0)$ \\
Coarse mode & 9.11 & 2.52 & 0 \\
brown carbon & $(1.97)$ & 26.45 & $(0)$ \\
Liquid water & 21.85 & 9.62 & 1356 \\
& $(4.26)$ & 51.23 & $(0.79)$ \\
\hline
\end{tabular}


average arises from the coarse mode of scattering aerosol family, with a mean detection score of 21.91 and a standard deviation of 4.26 (Table 6). It is also the most represented choice of the algorithm, with $69.23 \%$ of pixels assigned to this class, while the second most recurrent detected class is the accumulation mode of scattering aerosols, with a mean score of 21.87 and a standard deviation of 4.26 , but it just concerns $18.43 \%$ of the pixels from the image, which represents a large gap. This ensures the best model for the aerosol plume seen in the scene is the coarse mode of scattering aerosol.

Figure 8 presents the signature of the three most commonly detected classes (computed with our model), accumulation and coarse modes of scattering aerosol and fine mode of brown carbon, compared to the differential radiance spectrum from the mean pixels taken inside and outside the plume. This explains the relative confusion in the results: from 0.42 to $0.49 \mu \mathrm{m}$, the mean pixel from the image has a spectral behaviour comparable to the one of the fine mode brown carbon with an increase of the differential radiance. From 0.49 to $0.6 \mu \mathrm{m}$, the value decreases slowly as a mix between brown carbon and accumulation mode scattering aerosol. Thereafter, the signal is still decreasing as the coarse mode scattering aerosol (in contrast to its accumulation mode which remains constant or even increases slightly). These observations lead to the conclusion that a single mode in our modelling aerosol families is certainly not sufficiently accurate, or that it is even necessary to consider a mixture of some families.

This first case is fully constraint with a comfortable knowledge of the ground under the plume, here the water with a reflectance assumed as spatially invariant. The

Table 7. CTMF scores in the plume and statistics for the ten aerosol classes on area 2 (in bold: outstanding values discussed in the text).

\begin{tabular}{lccc}
\hline Class & $\begin{array}{c}\text { Mean CTMF score } \\
\text { (standard deviation) }\end{array}$ & $\begin{array}{c}\text { Min and max } \\
\text { CTMF scores }\end{array}$ & $\begin{array}{c}\text { Number of pixels with } \\
\text { the highest score } \\
\text { (value in \%) }\end{array}$ \\
\hline Fine mode & -0.99 & -4.29 & 0 \\
absorbing aerosol & $(0.94)$ & 3.19 & $(0)$ \\
Accumulation mode & -1.24 & -4.45 & 0 \\
absorbing aerosol & $(0.93)$ & 3.01 & $(0)$ \\
Coarse mode & -1.22 & -4.42 & 0 \\
absorbing aerosol & $(0.93)$ & 3.02 & $(0)$ \\
Fine mode & $\mathbf{2 . 3 8}$ & 0.00 & 1883 \\
scattering aerosol & $(0.74)$ & 5.24 & $\mathbf{( 5 4 . 1 2 )}$ \\
Accumulation mode & 1.80 & -0.95 & 122 \\
scattering aerosol & $(0.81)$ & 5.05 & $(3.51)$ \\
Coarse mode & 1.82 & -0.90 & 77 \\
scattering aerosol & $(0.82)$ & 5.15 & $(2.21)$ \\
Fine mode & $\mathbf{2 . 1 7}$ & -1.04 & 1355 \\
brown carbon & $(0.82)$ & 4.96 & $(\mathbf{3 8 . 9 5 )}$ \\
Accumulation mode & -1.22 & -4.39 & 0 \\
brown carbon & $(0.85)$ & 1.94 & $(0)$ \\
Coarse mode & -1.47 & -4.35 & 0 \\
brown carbon & $(0.88)$ & 1.69 & $(0)$ \\
Liquid water & 1.88 & -0.89 & 42 \\
& $(0.81)$ & 5.18 & $(1.21)$ \\
\hline
\end{tabular}


challenge for industrial scenes concerns the large number of soils that can be encountered as shown below.

\subsubsection{CTMF application for aerosol properties retrieval above complex background (close to the plant)}

Results outside the plume are more noisy than the previous example but detection scores are still averaging to 0 with a standard deviation of 1.

Inside the plume, as shown in Figure 9(c), the highest detection scores are also obtained for the scattering aerosol classes (with a mean CTMF score of 2.38 for $54.12 \%$ of positive detections) with the fine mode of brown carbon (mean CTMF score of $2.17 \%$ and $38.95 \%$ of positive detections), but the noise do not allow to determine with confidence the mode between those we defined from the mean scores or the minimum and maximum values (Table 7). It is mainly due to the high spatial heterogeneity of the ground which decreases the quality of the classification (Vidot 2005).

This uncertainty about the class highlights the need of a very precise ground classification in order to compute mean ground reflectance for each aerosol signature researched. Here, some mistakes are made between dark vegetation and shadows (Figure $9(b)$ ) as well as inside the water class with different depths (as seen on

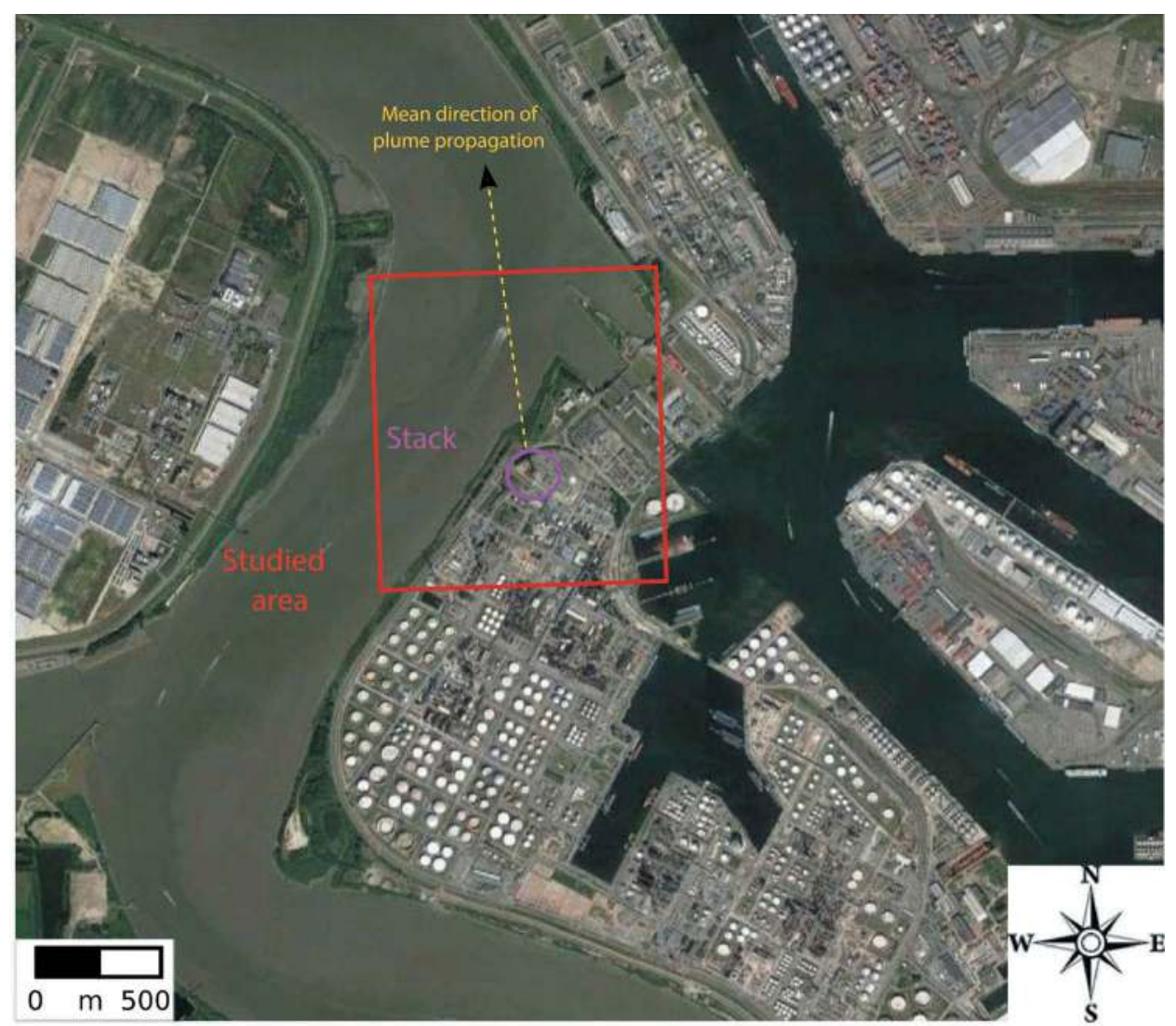

Figure 10. Overview of the Total Fina plant in Antwerp (screenshot from Google Earth). 
Figure 9(a)) affecting the mean reflectance. It does not seem to impact the CTMF scores (even if the brightness of the sand near the coast is mixing with the plume) but the classification below the plume is affected: most of the pixels concerned are classified as water (or as vegetation for a few of them) whereas there are more brighter and artificial surfaces visible on the right of the image.

The conclusions for the CASI test case are as follows. Near the stack, we detect a plume composed of mixing scattering and brown carbon aerosols in a fine mode (with detection scores of, respectively, 54\% and 39\%). Away from the stack, the detection scores lead to consider a dominant scattering aerosol with coarse mode (with a detection score of $69 \%)$.

\subsection{AHS image over Antwerp, Belgium}

\subsubsection{Data description}

The industrial site of Antwerp is located along the eastern bank of the Scheldt River in northern Belgium, close to the Dutch border. It is the largest petrochemical complex in

(a)

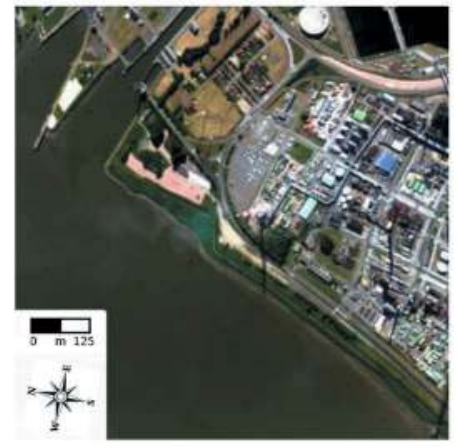

(b)

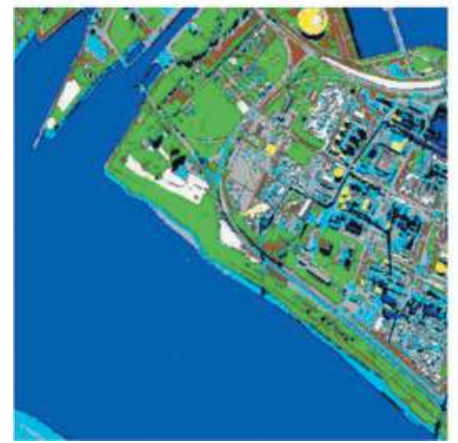

(c)

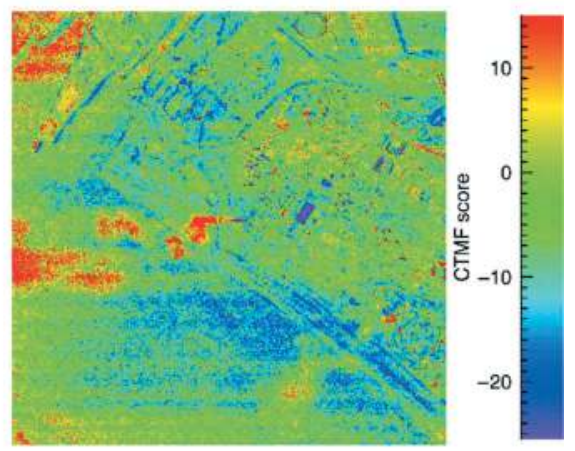

(d)

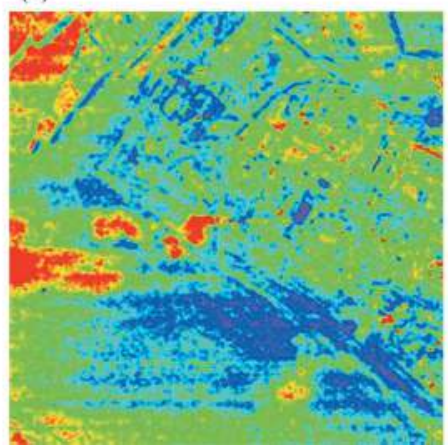

Figure 11. CTMF applied to Antwerp industrial site: (a) RGB composition of the studied area; (b) $k$-means classification result with 9 ground classes (water in blue, vegetation in green, two types of bright materials in white and yellow, bare soil in brown, bitumen and artificial surfaces in shades of grey, coastal zones in cyan, shadows in black); (c) the highest CTMF score, here the class of fine mode brown carbon class; (d) CTMF score map of fine mode brown carbon after applying low pass $3 \times 3$ filter. 
Table 8. Parameters for the AHS image in Antwerp, used for MODTRAN simulations.

\begin{tabular}{ll}
\hline Sensor altitude $(\mathrm{km})$ & 1.37 \\
View azimuth and zenith angles $\left({ }^{\circ}\right)$ & 0 (nadir) \\
Solar azimuth angle $\left({ }^{\circ}\right)$ & 134.5 \\
Solar zenith angle $\left(^{\circ}\right)$ & 34.3 \\
Atmospheric model & Mid-Latitude Summer \\
Mean water vapour content $\left(\mathrm{g} \mathrm{cm}^{-2}\right)$ & 1.03337 \\
Background aerosols model & Urban (visibility: $80 \mathrm{~km}$ ) \\
Plume's theoretical extent altitudes used for simulations $(\mathrm{m})$ & 20 to 90 \\
\hline
\end{tabular}

Europe and the second worldwide. A flight campaign was conducted the 16 June 2005 over the chemical site with the AHS-160 spectrometer (Airborne Hyperspectral Scanner), from visible to long-wavelength infrared (LWIR) with 80 contiguous channels from 0.4 to $15 \mu \mathrm{m}$, the main objective was to study emitted gases. The complete image covers $50 \mathrm{~km}^{2}$, thanks to a flight altitude equal to $1370 \mathrm{~m}$ with a spatial resolution of $3.5 \mathrm{~m}$ at nadir. Here, we just focus on the Total Fina plant (located on Figure 10) and especially on a stack which emits $\mathrm{SO}_{2}$. During the overflight, the plume was heading north direction (represented by the yellow dotted arrow on Figure 10).

Shimoni et al. (2007) summarizes the flight campaign and data acquisition, and reports the detection of a $\mathrm{SO}_{2}$ plume (gas) with the Continuum Interpolated Band Ratio (CIBR) method (Carrère and Conel 1990; Green, Carrère, and Conel 1990). Seeing a non-continuous white plume over the river on AHS data (Figure 11(a)), the goal is here to study aerosols linked to this release.

Table 9. CTMF scores in the plume and statistics for the ten aerosol classes on the AHS image (in bold: outstanding values discussed in the text).

\begin{tabular}{lccc}
\hline Class & $\begin{array}{c}\text { Mean CTMF score } \\
\text { (standard deviation) }\end{array}$ & $\begin{array}{c}\text { Min and max } \\
\text { CTMF scores }\end{array}$ & $\begin{array}{c}\text { Number of pixels with } \\
\text { the highest score } \\
\text { (value in \%) }\end{array}$ \\
\hline Fine mode & 0.32 & -4.51 & 78 \\
absorbing aerosol & $(0.99)$ & 4.40 & $(1.40)$ \\
Accumulation mode & 0.21 & -4.92 & $\mathbf{1 6 0}$ \\
absorbing aerosol & $(0.99)$ & 4.27 & $(2.86)$ \\
Coarse mode & 0.22 & -4.67 & 23 \\
absorbing aerosol & $(0.99)$ & 4.20 & $(0.41)$ \\
Fine mode & $\mathbf{1 . 0 8}$ & -2.25 & $\mathbf{1 2 7 5}$ \\
scattering aerosol & $(0.95)$ & 4.62 & $\mathbf{( 2 2 . 8 0 )}$ \\
Accumulation mode & 0.86 & -2.12 & 140 \\
scattering aerosol & $(0.88)$ & 4.54 & $(2.50)$ \\
Coarse mode & 0.90 & -2.05 & $\mathbf{6 5 0}$ \\
scattering aerosol & $(0.88)$ & 4.54 & $(11.63)$ \\
Fine mode & $\mathbf{1 . 2 1}$ & -2.26 & $\mathbf{2 9 0 1}$ \\
brown carbon & $(0.95)$ & 4.54 & $\mathbf{( 5 1 . 8 9 )}$ \\
Accumulation mode & -0.88 & -4.81 & 264 \\
brown carbon & $(0.99)$ & 2.72 & $(4.72)$ \\
Coarse mode & -0.85 & -5.08 & $\mathbf{4 9}$ \\
brown carbon & $(0.99)$ & 2.32 & $(0.88)$ \\
Liquid water & 0.88 & -2.12 & 51 \\
& $(0.88)$ & 4.53 & $(0.91)$ \\
\hline
\end{tabular}




\subsubsection{Atmospheric parameters and ground reflectance estimation}

The results of the atmospheric correction, to process the grip of the scene around the stack (Figure 11(a)), are summarized in Table 8. The $k$-means classification was performed with nine ground classes: water, vegetation, two classes of bright artificial materials, dark artificial materials, bare soil, bitumen, coastal zones, and shadows. It is important to note that the water class brings together the turbid waters of the river and the quiet (darker) ones of the artificial docks of the harbour (in the upper right part of the Figure 11(a)). The radiometric quality of the image ensures a better classification (Figure 11(b)) compared to the one for the CASI image over Fos-sur-Mer. Simulation conditions for MODTRAN computations are given in Table 8. Of the 80 AHS channels, only the first 20 were used here (on the range from 0.4 to $1.0 \mu \mathrm{m}$ ). But the low optical thickness of the plume makes it invisible for spectral channels beyond $0.7 \mu \mathrm{m}$.

\subsubsection{CTMF application for aerosol properties retrieval}

Even if the ground classification is here of better quality, the industrial plume observed is much thinner than the one at Fos-sur-Mer. CTMF score maps (as in Figure 11(c)) reveal that it is divided into three or four parts, probably diffused by changing winds (no data is available concerning the wind). At a local scale, as for Fos-sur-Mer, CTMF results are noisy and need to be studied at a more global scale, by using mean scores inside the plume. The three main parts of the plume have been hand-discarded, using CTMF scores, into a single region of interest on ENVI.

CTMF statistics are summarised in Table 9. In this case, we observe that the whole aerosol classes have approximatively the same minimum and maximum scores, with a high standard deviation value. The mean scores clearly identify two main families: fine

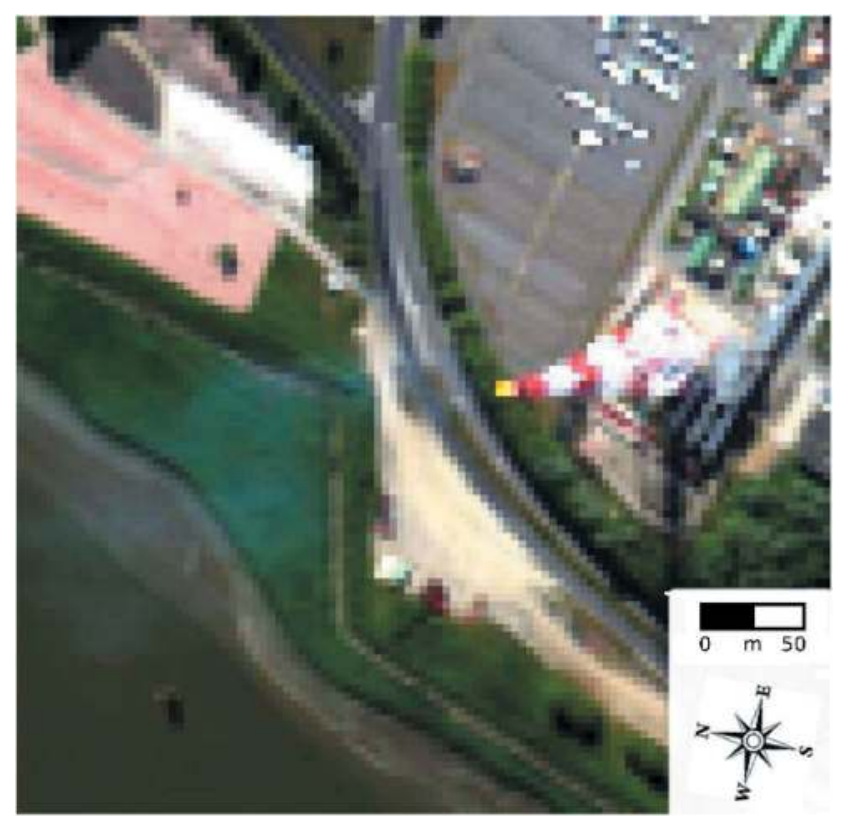

Figure 12. Detail of the AHS image over the flare emitting the plume with the visible burning in the centre and the plume extending to the left. 


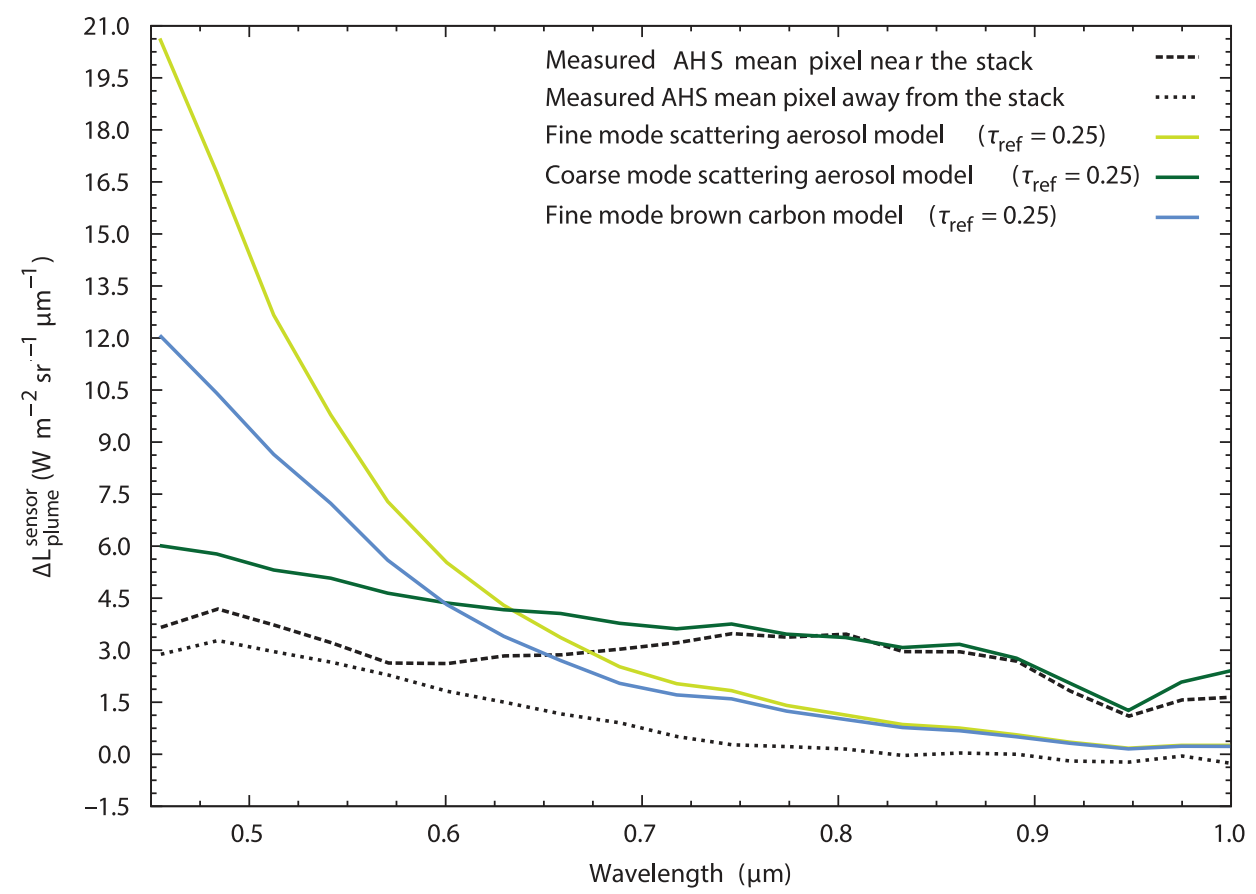

Figure 13. Comparison of the at-sensor radiance differential from computed fine mode scattering aerosol, fine mode brown carbon with our model and two at-sensor radiance differential spectra collected over the plume compared to the reference spectrum outside, on the AHS image, one near the stack and a second far away.

mode scattering aerosol and fine mode brown carbon have, respectively, 1.08 and 1.21 values when the other families are less than 0.9. This is confirmed by the number of pixels detected as belonging to one of these two classes: 1275 pixels ( $22.80 \%$ of the total in the plume) are associated to the fine mode scattering aerosol, and 2901 (51.89\%) correspond to the fine mode brown carbon. If the stack was suspected to emit sulfates (and so scattering aerosols), this is coherent to observe a mixing as the brown carbon with the higher score.

Indeed, the flare has clearly a visible flame on the AHS image during the acquisition (Figure 12), and the burning could produce a certain amount of absorbing particles which impact on the aerosol class detection. This is why, unlike the site of Fos-sur-Mer, all aerosol classes have at least a few pixels detected (from 49 for coarse mode brown carbon, to 160 for accumulation mode absorbing aerosol and 650 for coarse mode scattering aerosol). This result cannot be seen on the RGB (red green blue) composition.

Finally, the results obtained for the petrochemical complex at Antwerp consist in a plume of a fine mode of brown carbon, related to the observation of the combustion of scattering particles in the immediate vicinity of the stack and with high spatial resolution. But Figure 13 highlights the phenomenon pointed out previously (all classes are detected as the most likely in a significant number of pixels), with the two spectra collected in the different main parts of the plume as pointed in the beginning of this section. The spectrum collected near the flare has a dynamic close to the signature of 


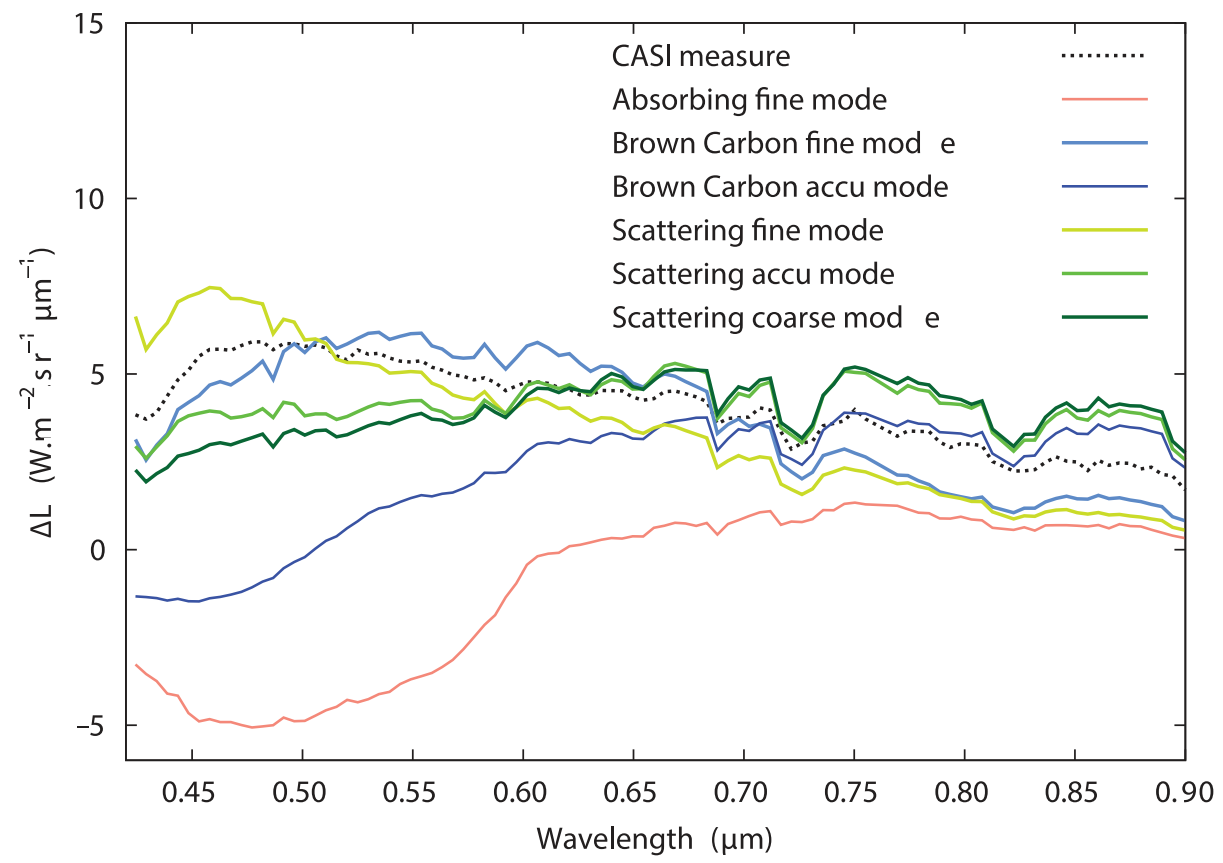

Figure 14. Comparison between generic modelling spectral signatures and measured ones over the CASI image.

the coarse mode scattering aerosol. The second spectrum considered away from the flare has a lower level of radiance, closer to those of fine mode scattering aerosol or fine mode brown carbon. This explains that the filter can identify in several pixels these signatures and suggests that the observed plume could contain a mixture of our families. If the results in Table 9 are computed over the whole plume, we can guess a relative evolution in the composition of the plume (from a dominant scattering aerosol to a mixing detected as brown carbon). This subject is discussed in the next section.

\section{Mapping of aerosols properties and AOT}

In the last two parts, we have described a method to detect aerosol plumes and to estimate globally their main properties. In this part, we aim to estimate more precisely aerosol plume properties using a multimodal distribution based on the aerosol impact model described below.

\subsection{CASI data}

\subsubsection{Spectral analysis of aerosol signatures}

From the CASI scene (Figure 7(a)), we have estimated mean aerosol impact on radiance and retrieved reflectance (from atmospheric corrected data) corresponding to the plume centre. The differential radiance between on-plume and off-plume measurements from the CASI image is written $\Delta L_{\text {measured }}$. The mean radiance signatures of aerosol assuming 


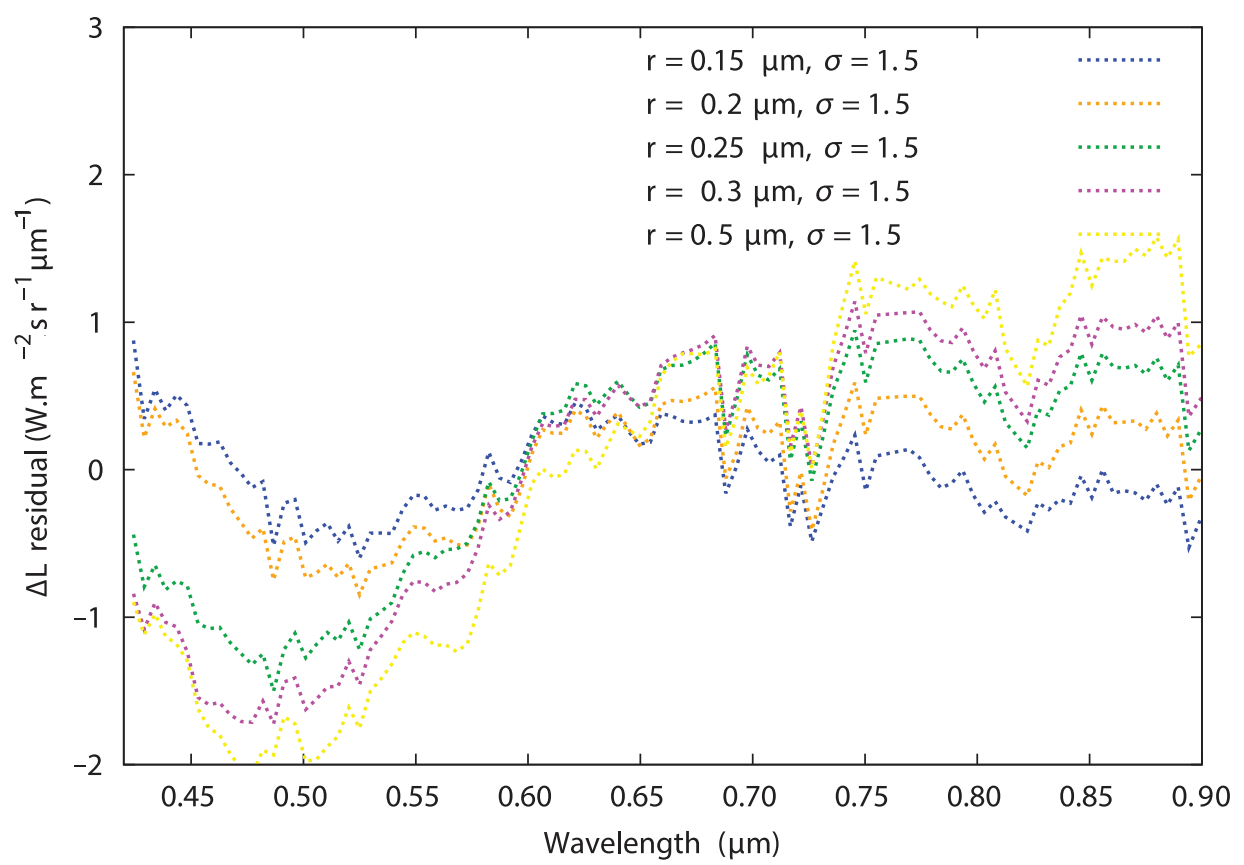

Figure 15. Difference between model spectral signature of scattering aerosols from 0.15 to $0.5 \mu \mathrm{m}$ radius and image measurement.

that water has the same mean optical properties under and outside the plume are plotted in Figure 14 (blue dotted line).

We have seen in section 3 that aerosol signatures can be estimated at different optical depths from pre-calculated radiative compounds for any aerosol distribution and type. Using a single linear retrieval algorithm, the optical depth at $550 \mathrm{~nm}$, which minimizes the difference between aerosol signature and measure, can also be estimated.

For most of the aerosols described in section 2, the best fit between several aerosol classes' signatures and residuals $\left(\Delta L_{\text {model }}-\Delta L_{\text {measured }}\right)$ is shown in Figure 15 . The retrieved optical depth is about 0.4 and one can also notice that none of the predefined aerosol modes (from section 2) fits well with plume mean signature. However, the main contribution to measured signature comes from scattering aerosols with a mean radius in the range $[0.1 ; 0.5] \mu \mathrm{m}$. The next step is then to estimate the best scattering aerosols size distribution in term of spectral fit of the measure.

For mean radii from 0.1 to $0.5 \mu \mathrm{m}$ (by steps of $50 \mathrm{~nm}$ ) and assuming $\sigma_{\mathrm{m}}=1.5$, the residual $\Delta L_{\text {model }}-\Delta L_{\text {measured }}$ evolution with size is shown in Figure 15 . The best fit corresponds to a mean radius of $0.2 \mu \mathrm{m}$ (orange dot line). However, it can be noticed that there is an important impact from 400 to $600 \mathrm{~nm}$ in the model signature not seen by the measure. This is correlated to the water reflectance value that is significant only in this spectral range. There is a systematic underestimation by the model in this spectral domain that can not be corrected by adding any kind of other aerosols.

Our hypothesis is that we must not consider an infinite plume for the model. Indeed, in this case, due to the sun zenith angle $\left(71^{\circ}\right.$ from the nadir), the modelling downward path inside the plume is up to three times $\left(1 / \cos \left(71^{\circ}\right)\right)$ higher than upward path in the 


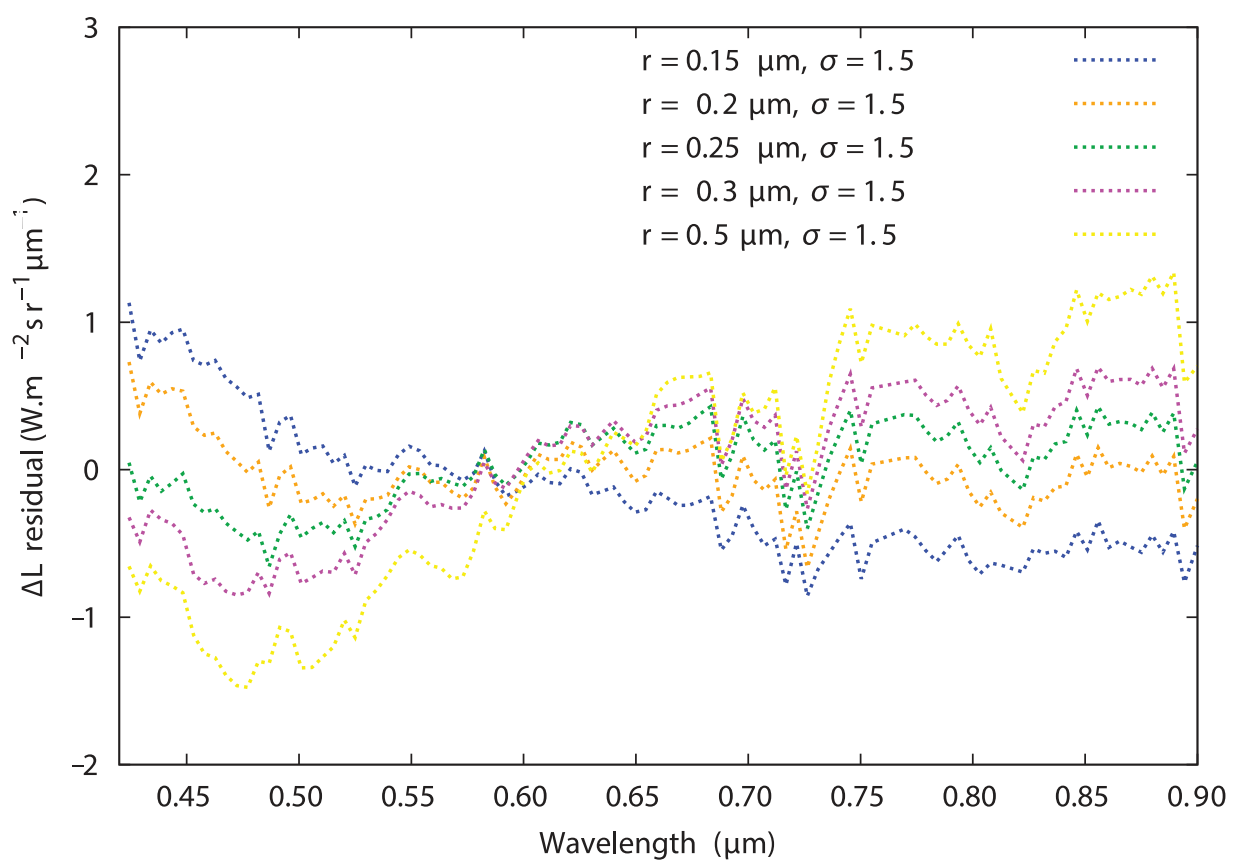

Figure 16. Same as Figure 15 but assuming that downlooking direct flux does not cross the plume.

Table 10. Mean contribution to AOT of the 3 selected modes in the plume.

\begin{tabular}{lccc}
\hline Aerosol family & $\begin{array}{c}\text { Radius } \\
(\mu \mathrm{m})\end{array}$ & $\begin{array}{c}\text { Standard } \\
\text { deviation }(\mu \mathrm{m})\end{array}$ & $\begin{array}{c}\text { Contribution } \\
\text { to AOT }\end{array}$ \\
\hline Scattering & 0.2 & 1.5 & 0.27 \\
Brown carbon & {$\left[0.05^{*}-0.1\right]$} & 1.5 & 0.035 \\
Scattering & {$\left[0.5^{*}-1.0\right]$} & 1.5 & 0.02 \\
\hline
\end{tabular}

* It corresponds to the best fit but the mentioned value gives a very close residual.

plume, if we consider an infinite plume. When assuming a finite plume and only upward path inside the plume, the model can be rewritten as

$$
\Delta L_{\text {plume }}^{\text {sensor }}(\lambda)=\Delta L_{\text {plume }}^{\text {atm }}(\lambda)+\frac{\rho_{\text {soil }}(\lambda)}{\pi} E_{\text {plume }}^{\text {surf }}(\lambda) \Delta T_{\text {plume }}^{\text {atm }}(\lambda)
$$

From this hypothesis, Figure 16 shows that the high impact of water reflectance from 0.4 to $0.6 \mathrm{~nm}$ on the modelling signature has been reduced and that the $200 \mathrm{~nm}$ radius size scattering aerosol distribution impact reproduces well aerosol measured signature up to $500 \mathrm{~nm}$. This change of hypothesis does not revise the best distribution, which is still valid for $r_{\mathrm{m}}=0.2 \mu \mathrm{m}$ and $\sigma_{\mathrm{m}}=1.5$.

\subsubsection{Multimodal aerosols contributions}

From Figure 16, the residual of the best single mode fit increases significantly from 0.42 to $0.50 \mu \mathrm{m}$. So, using a non-negative linear iterative algorithm, we look for a multimodal 
(a)

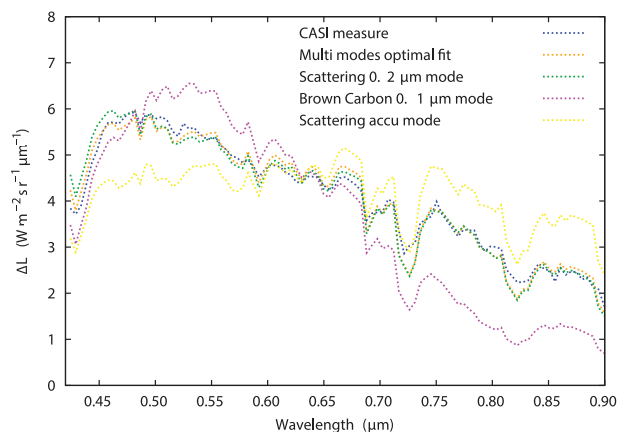

(b)

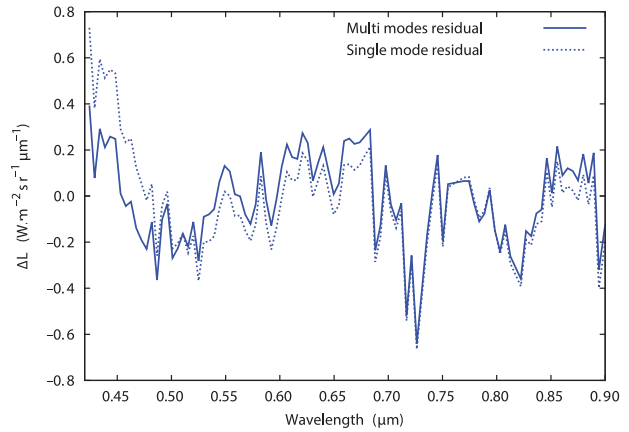

Figure 17. (a) Multimodal retrieved signature and relative contribution of the $0.2 \mu \mathrm{m}$ scattering mode (green), scattering accumulation mode (yellow) and brown carbon fine mode (pink) to the aerosol radiative impact. (b) Multimodal associated residual compared to single mode residual.

(a)

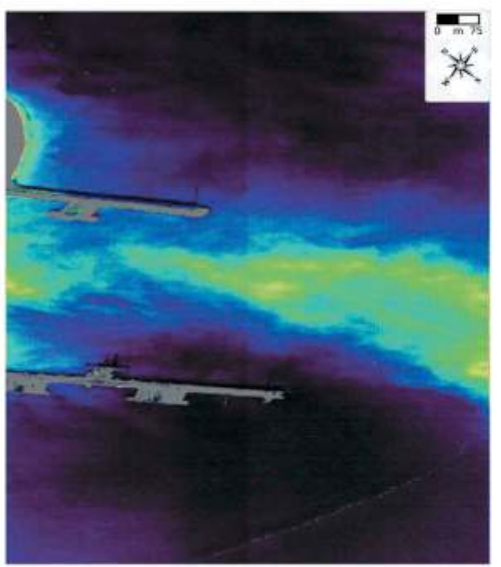

(b)

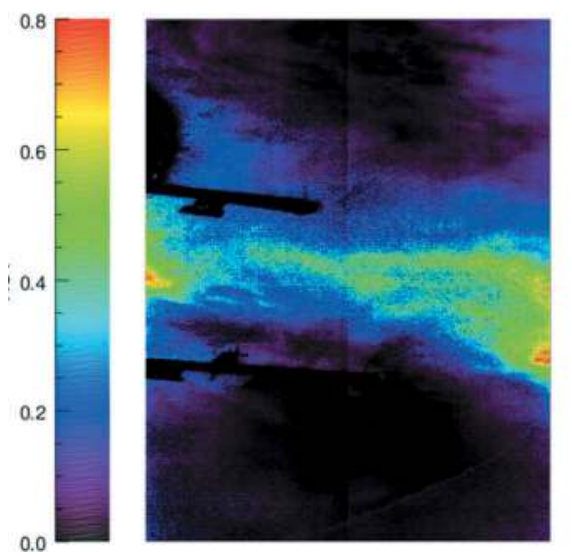

(c)

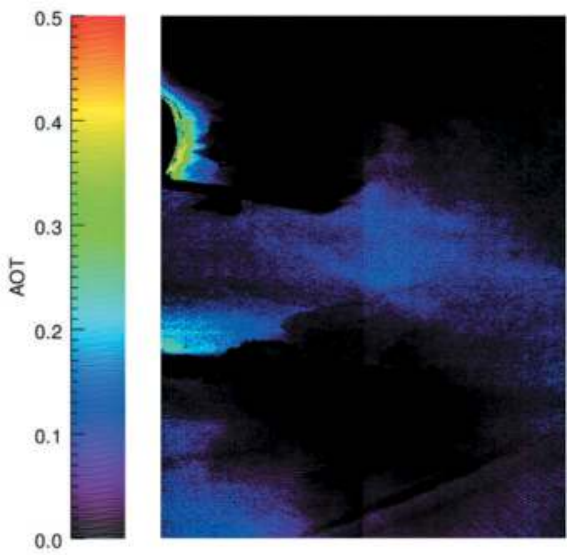

(d)

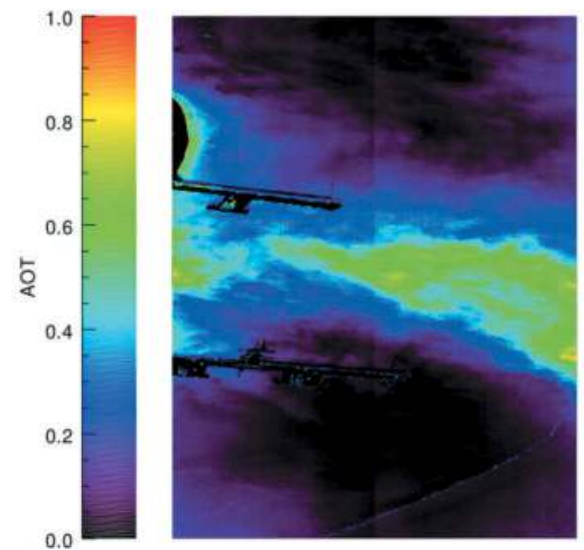

Figure 18. AOT retrievals over Fos (area 1): (a) Aerosol plume AOT [0.0; 0.5$]$ surimposed to $550 \mathrm{~nm}$ CASI band radiance, (b) Scattering $0.2 \mu \mathrm{m}$ mode contribution to AOT [0.0; 0.3], (c) $0.5 \mu \mathrm{m}$ mean radius scattering mode contribution to AOT [0.0; 0.1$]$, (d) Total aerosol plume AOT [0.0; 0.5]. 
distribution from different types of aerosols which can improve the fit with measured aerosol signature. A database of aerosol properties and radiative compounds impact calculated for an optical depth of 0.5 is used. Three types of aerosol have been considered: high absorbing (soot), brown carbon and non-absorbing (scattering only), with mean radius size from $50 \mathrm{~nm}$ to $1.0 \mu \mathrm{m}$ (assuming a fixed $\sigma_{\mathrm{m}}=1.5$ ). These aerosols have been added to the principal contributor found previously $\left(r_{\mathrm{m}}=0.2 \mu \mathrm{m}\right)$. The best fit corresponds to a three modes distribution described in Table 10.

In each case, the principal contributor has not changed. The second mode is clearly a fine mode brown carbon aerosol with a radius between 0.05 and $0.1 \mu \mathrm{m}$. The mode 3 corresponds to accumulation or coarse mode scattering aerosol (the accuracy on the mean radius is not high due to a lack of short wavelength infrared - SWIR - spectral range data).

Figure 17 shows the modelling multimodal signatures, the measured aerosol signatures, and residuals. The model reproduces very well the aerosol signature with a residual mostly due to instrumental and atmospheric noises. The slope decrease around $450 \mathrm{~nm}$ is well reproduced and the residual does not diverge for short wavelengths in comparison with single mode residual.

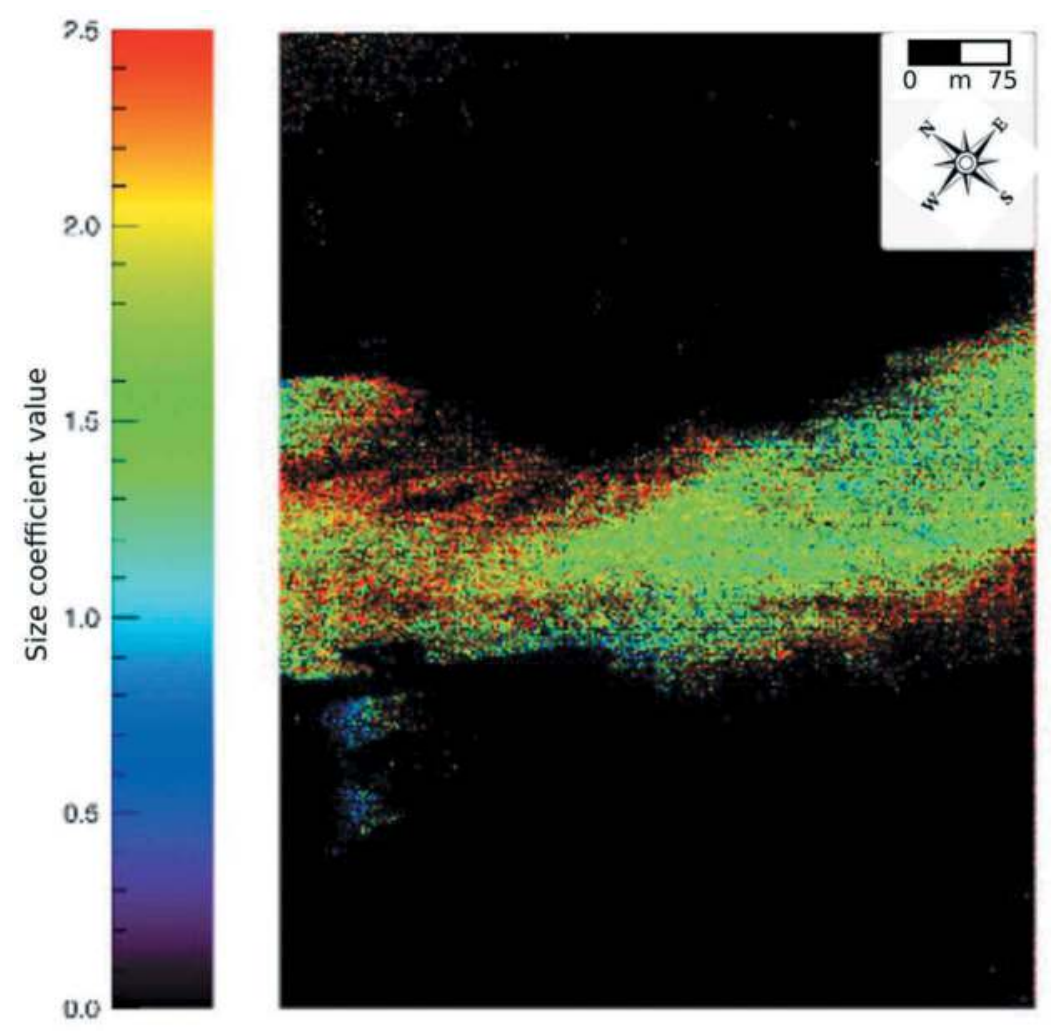

Figure 19. Map of size coefficient $a_{\text {size }}$ associated with size distribution of aerosols. Red tones correspond to high coefficient values $(0.25)$ and blue tones to lower ones (0.15). 
The multimodal analysis has reduced mean radiance residual amplitude from 1.5 to 0.3 (factor 5) and makes us able to estimate AOT for PM1 (Particulate Matter of less than $1 \mu \mathrm{m}$ in diameter) aerosols.

\subsubsection{Map of aerosol properties}

From this three modes distribution using the same non-negative iterative linear algorithm, we can estimate for each pixel the total AOT and the relative contribution of each mode. Figure 18 shows the AOT map of CASI plume over the Mediterranean Sea using the three initial multimodal distributions and the map of relative contribution of each mode. It appears, as expected, that the

$0.25 \mu \mathrm{m}$ mode contribution is predominant all over the plume, however, one can notice that accumulation mode contribution is more important in the downwind part of the plume. Assuming that refractive properties of the plume do not spatially change, we can estimate that spatial variation of the spectral radiative impact of aerosols is linked to size distribution. From this point, we estimate a size coefficient $a_{\text {size }}$ whose expression is close to Ångström coefficient (Ångström 1929) but applied directly to plume radiative impact spectral signature (as spectral AOT is not measured or retrieved directly from the hyperspectral measurements):

$$
a_{\text {size }}=-\frac{\log _{10}\left(\Delta L_{\text {plume }}^{\text {sensor }}(\tau=550 \mathrm{~nm})\right)-\log _{10}\left(\Delta L_{\text {plume }}^{\text {sensor }}(\tau=650 \mathrm{~nm})\right)}{\log _{10}(550)-\log _{10}(650)}
$$

For example, this coefficient has a value of 5 for the model scattering fine mode, value around 1 for the model scattering accumulation mode and around 0 for coarse mode. Figure 19 shows the size coefficient map for the whole plume. A slight decrease is observed from 0.25 to 0.15 of $a_{\text {size }}$ along the plume. This change is well correlated with the retrieved slight increase of accumulation mode contribution to the total AOT. One can conclude that the accumulation process is ongoing in this plume.

(a)

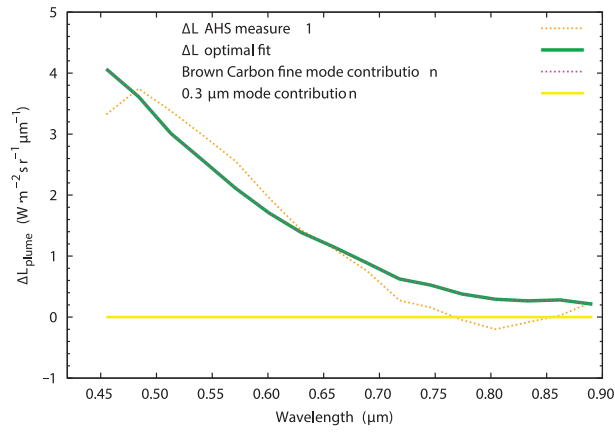

(b)

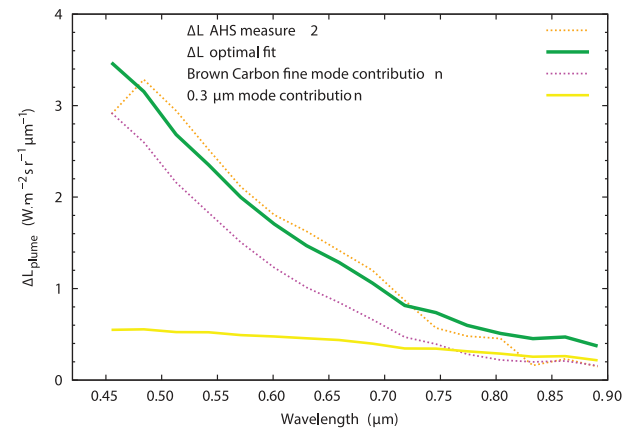

Figure 20. Contribution of the two retrieved modes in the measured plume radiance impact: (a) case of an area near the emission point, (b) case of an area far away from the emission point but still in the plume; the model impact is in dotted orange, optimal fit in green, fine mode and $0.3 \mu \mathrm{m}$ mode impacts are in dotted pink and yellow, respectively. 
(a)

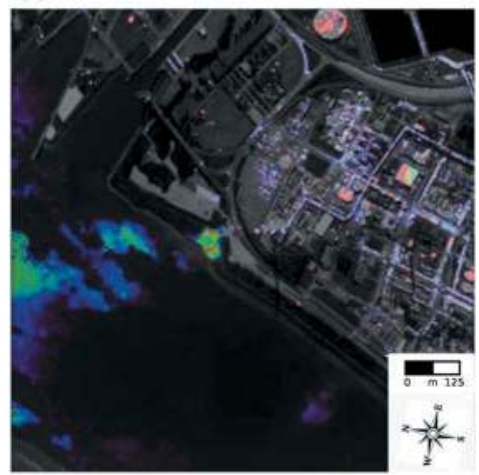

(b)

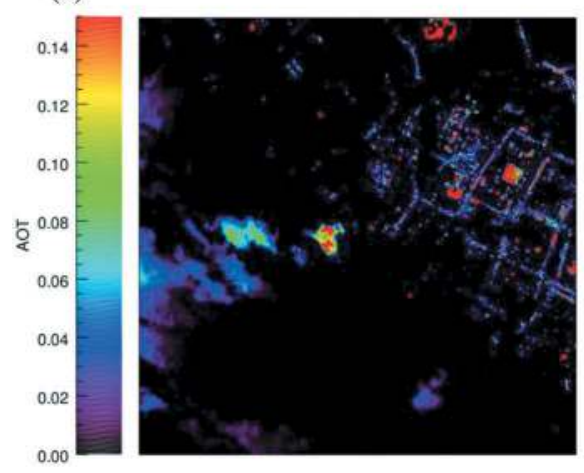

(c)

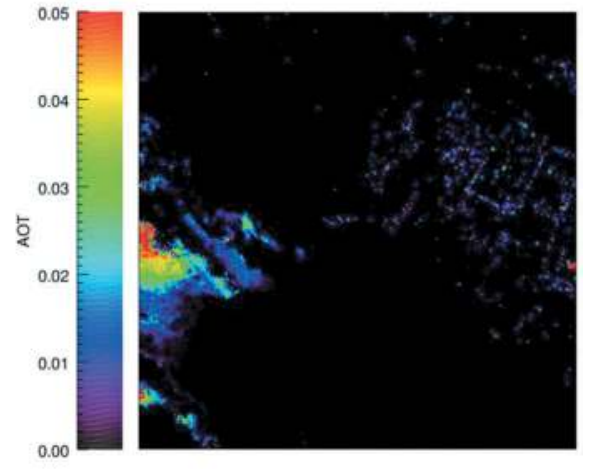

(d)

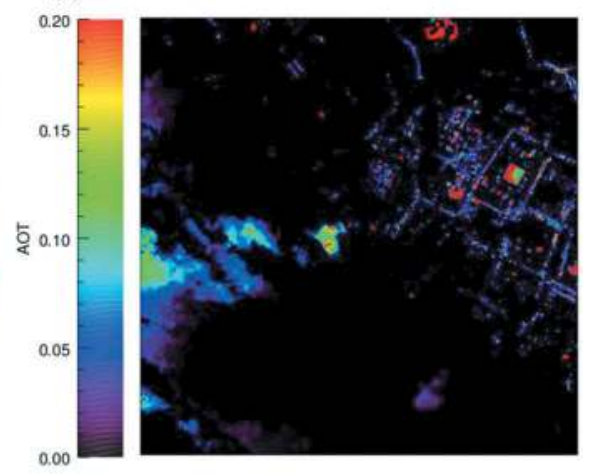

Figure 21. AOT retrievals over Antwerp: (a) Aerosol plume properties from Antwerp refinery, (b) Brown Carbon fine mode contribution to AOT, (c) $0.3 \mu \mathrm{m}$ mean radius sulfate mode contribution to AOT, (d) Total aerosol plume AOT [0.02; 0.15].

\subsection{AHS data}

\subsubsection{Spectral analysis of aerosol signatures}

In this case, we have shown that fine mode brown carbon and fine mode scattering aerosol (sulfate) get the best CTMF results in part 5 . As detailed in the previous case, we have used an iterative non-negative inversion algorithm to estimate the best modes which contributes to aerosol signature. Only two modes are necessary to optimize the fit between model and measurement, the principal mode corresponds to the fine mode brown carbon mode and the second one is the $0.3 \mu \mathrm{m}$ radius $\left(\sigma_{\mathrm{m}}=1.5\right)$ sulfate mode.

Figure 20 represents two different results (at different distances from the source) using these two modes. For the case of the area near the emission point, contribution of $0.3 \mu \mathrm{m}$ mode can be neglected, however at $100 \mathrm{~m}$ away, contribution of the $0.3 \mu \mathrm{m}$ radius mode is about $30 \%$ in the total optical signature.

\subsubsection{Spectral analysis of aerosol signatures}

Then, the mapping of retrieved properties has been applied in the whole scene. Figure 21 shows the final results in terms of the total aerosol optical thickness of the 


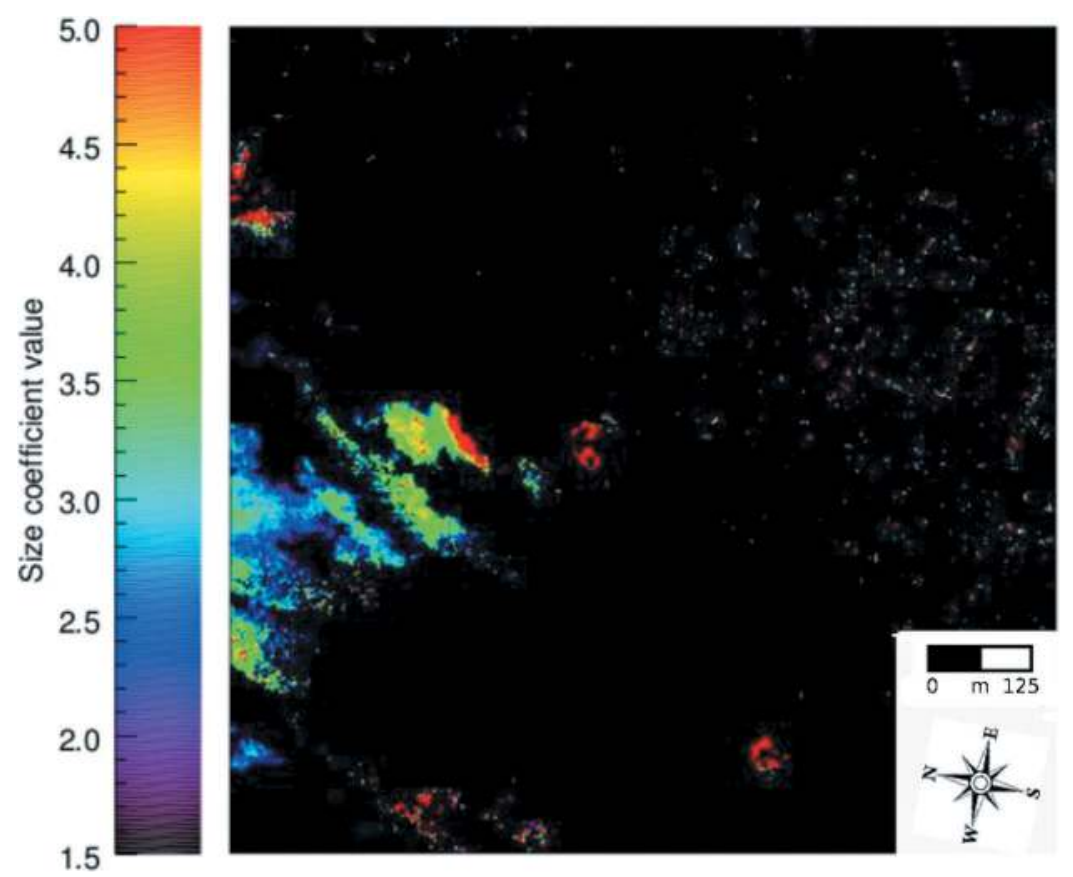

Figure 22. Map of size coefficient $a_{\text {size }}$ associated with size distribution of aerosols. Red values correspond to high coefficient (fine mode is around 5) and blue values to lower values (coarse mode is around 1).

plume and relative contribution of fine and coarse modes. The plume is very well detected from the scene and we can follow spatial evolution of optical signature one could be linked to aerosols properties. Indeed, fine mode AOT contribution decreases with distance from the source from 0.15 to 0.05 but coarse mode AOT contribution increases from 0 near the source to 0.05 in the end of the plume. The total aerosol AOT estimated varies from 0.15 down to 0.05 depending on the distance to the source and wind turbulences.

The spatial evolution of $0.3 \mu \mathrm{m}$ mode contribution to AOT can be correlated with accumulation process of fine sulfates (and certainly with other aerosols already present in the air) emitted by the refinery. In order to confirm these results, we have evaluated, as previously for the CASI case, the size coefficient to measure relative changes in the size distribution of aerosols.

Figure 22 shows evolution map of the size coefficient get directly from the measurements. The dynamic of the spatial evolution is more important than in the CASI data. We observe a decrease of $a_{\text {size }}$ with distance to the source, from 5 (typical value of fine mode) near the emission point to 2 (typical value of accumulation mode is around 1) $100 \mathrm{~m}$ away from the source. It confirms the previous results of relative contribution to AOT. One may conclude that, in this image, the beginning of the accumulation process of fine sulfates emitted by the refinery can be observed. One can also confirm that the tiny plume in the right bottom side of the scene (seen in most of the previous figures) is mostly a fine mode scattering plume. 


\section{Conclusion and future work}

In order to study optically thin plumes of aerosols emitted by an industrial complex, a semi-analytical model of their radiative impact is developed and coupled with the Cluster-Tuned Matched Filter algorithm, intended to characterize their microphysical properties and optical thickness. For ten aerosol classes with one mode chosen as reference industrial emissions, we show that we can describe plumes formed by these particles for AOT ranging from 0.0 to 0.4 , the best results being obtained over dark surfaces as water, for a model designed with a reference AOT of 0.25 . The atmospheric spherical albedo variations due to the aerosol plume should not be neglected to ensure sufficient model performances assuming on bright surfaces for infinite spatial spread plume. However, the spatial spread of the plume is finite and its impact on the downward fluxes can be neglected when applying to real data. In this case, we can estimate that atmospheric spherical albedo change may be neglected.

We have shown that the CTMF algorithm can be used to obtain a first estimation of the plume spatial extension and a first estimation of the main aerosol type for the two study cases. However, refining the detection results by using a multimodal distribution is then necessary to conclude on the aerosol mixture characteristics of the plume. We have developed a method based on the previous model using the CTMF results as a first guess to estimate more accurately the plume aerosol mixture. It has been applied on two test cases, firstly the metallurgical site of Fos-sur-Mer in France where we retrieved a mix of scattering and brown carbon particles with AOT ranging between 0.2 and 0.5 and a size distribution centred on $0.25 \mu \mathrm{m}$, and secondly over the petrochemical complex of Antwerp where we retrieved AOT decreasing from 0.15 to 0.05 along the plume with a size distribution centred on $0.1 \mu \mathrm{m}$ near the source. In the two cases, these results can be correlated to the secondary aerosols formation from primary ones and gas condensation.

Future work should consider the impact of atmospheric spherical albedo and a finite spatial plume including the sun position in order to model more precisely the plume impact, in particular for bright surfaces.

\section{Acknowledgments}

The CASI data over Fos-sur-Mer were funding by European Facility for Airborne Research (EUFAR) for the transnational access project "ValCalHyp" with the support of NERC for the airborne data acquisition. The AHS data over the port of Antwerp was collected during the TIRIS project under the funding of the Belgian Science Policy, BELSPO contract \# SR/20/075, and in collaboration with the Belgian Royal Military Academy.

\section{Disclosure statement}

No potential conflict of interest was reported by the authors.

\section{ORCID}

Pierre-Yves Foucher (1) http://orcid.org/0000-0002-0435-4573

Rodolphe Marion (10) http://orcid.org/0000-0001-5585-4335 


\section{References}

Alakian, A., R. Marion, and X. Briottet. 2008. "Remote Sensing of Aerosol Plumes: A Semi-Analytical Model." Applied Optics 47 (11): 1851-1866. doi:10.1364/AO.47.001851.

Alakian, A., R. Marion, and X. Briottet. 2009. "Retrieval of Microphysical and Optical Properties in Aerosol Plumes with Hyperspectral Imagery: L-APOM Method." Remote Sensing of Environment 113: 781-793. doi:10.1016/j.rse.2008.12.006.

Anderson, G. P., G. W. Felde, M. L. Hoke, A. J. Ratkowski, T. Cooley, J. H. Chetwynd, J. A. Gardner, et al. 2002. "MODTRAN4-based Atmospheric Correction Algorithm: FLAASH (Fast Line-Of-Sight Atmospheric Analysis of Spectral Hypercubes." Algorithms and Technologies for Multispectral, Hyperspectral and Ultraspectral Imagery VIII, Proceedings of the SPIE 4725:65-71.

Andreae, M., H. Annegarn, L. Barrie, J. Feichter, D. Hegg, A. Jayaraman, R. Leaitch, et al. 2001. "Aerosols, Their Direct and Indirect Effects." In Climate Change 2001: The Scientific Basis Contribution of Working Group I to the Third Assessment Report of the Intergovernmental Panel on Climate Change, edited by IPCC (Intergovernmental Panel on Climate Change), 881. UK and NY: Cambridge University Press.

Andreae, M. O., and A. Gelencsér. 2006. "Black Carbon or Brown Carbon? the Nature of LightAbsorbing Carbonaceous Aerosols." Atmospheric Chemistry and Physics 6: 3131-3148. doi:10.5194/acp-6-3131-2006.

Ångström, A. 1929. "On the Atmospheric Transmission of Sun Radiation and on Dust in the Air." Geografiska Annaler 11: 156-166.

Artaxo, P., C. Bretherton, G. Feingold, P. Forster, V.-M. Kerminen, Y. Kondo, H. Liao, et al. 2013. "Clouds and Aerosols." In Climate Change 2013: The Physical Science Basis - Working Group I Contribution to the Fifth Assessment Report of the Intergovernmental Panel on Climate Change, edited by IPCC (Intergovernmental Panel on Climate Change), 1535. UK and NY: Cambridge University Press.

Auer, A. H. Jr. 1976. "Observations of an Industrial Cumulus." Journal of Applied Meteorology 15: 406-413. doi:10.1175/1520-0450(1976)015<0406:OOAIC>2.0.CO;2.

Bohren, C. F., and D. R. Huffman. 1983. Absorption and Scattering of Light by Small Particles. New York: John Wily \& Sons.

Bojinski, S., D. Schläpfer, M. E. Schaepman, and J. Keller. 2002. "Aerosol Mapping over Rugged Heterogeneous Terrain with Imaging Spectrometer Data." Imaging Spectrometry VIII, Proceedings of the SPIE 4816: 108-119.

Bond, T. C., S. J. Doherty, D. W. Fahey, P. M. Forster, T. Berntsen, B. J. DeAngelo, M. G. Flanner, et al. 2013. "Bounding the Role of Black Carbon in the Climate System: A Scientific Assessment." Journal of Geophysical Research: Atmospheres 118:5380-5552.

Buchwitz, M., R. De Beek, S. Noël, J. P. Burrows, H. Bovensmann, O. Schneising, I. Khlystova, et al. 2006. "Atmospheric Carbon Gases Retrieved from SCIAMACHY by WFM-DOAS: Version 0.5 CO and $\mathrm{CH}_{4}$ and Impact of Calibration Improvements on $\mathrm{CO}_{2}$ Retrieval". Atmospheric Chemistry and Physics 6: 2727-2751. doi:10.5194/acp-6-2727-2006.

Carrère, V., and J. E. Conel. 1990. “Recovery of Atmospheric Water Vapor Total Column Abundance from Imaging Spectrometer Data around $940 \mathrm{Nm}$ - Sensitivity Analysis and Application to Airborne Visible/Infrared Imaging Spectrometer (AVIRIS) Data." Remote Sensing of Environment 44: 179-204. doi:10.1016/0034-4257(93)90015-P.

Chandrasekhar, S. 1960. Radiative Transfer. New York, NY: Dover Publications.

Charlson, R. J., S. E. Schwartz, J. M. Hales, R. D. Cess, J. A. Coakley Jr., J. E. Hansen, and D. J. Hofmann. 1992. "Climate Forcing by Anthropogenic Aerosols." Science 255 (5043): 423-430. doi:10.1126/science.255.5043.423.

Chavez, P. S. 1988. "An Improved Dark-Object Subtraction Technique for Atmospheric Scattering Correction of Multispectral Data." Remote Sensing of Environment 24 (3): 459-479. doi:10.1016/ 0034-4257(88)90019-3. 
Dennison, P. E., A. K. Thorpe, E. R. Pardyjak, D. A. Roberts, Y. Qi, R. O. Green, E. S. Bradley, and C. C. Funk. 2013. "High Spatial Resolution Mapping of Elevated Atmospheric Carbon Dioxide Using Airborne Imaging Spectroscopy: Radiative Transfer Modelling and Power Plant Plume Detection." Remote Sensing of Environment 139: 116-129. doi:10.1016/j.rse.2013.08.001.

Deschamps, A. 2012. "Caractérisation de panaches industriels par imagerie hyperspectrale." Ph.D. thesis, Université Pierre et Marie Curie, France.

Deschamps, A., R. Marion, X. Briottet, and P.-Y. Foucher. 2013. "Simultaneous Retrieval of $\mathrm{CO}_{2}$ and Aerosols in a Plume from Hyperspectral Imagery: Application to the Characterization of Forest Fire Smoke Using AVIRIS Data." International Journal of Remote Sensing 34 (19): 6837-6864. doi:10.1080/01431161.2013.809499.

Deschamps, A., R. Marion, P.-Y. Foucher, and X. Briottet. 2012. "Estimation of Aerosol Type from Airborne Hyperspectral Data: A New Technique Designed for Industrial Plume Characterization." Proc. SPIE 8534, Remote Sensing of Clouds and the Atmosphere XVII; and Lidar Technologies, Techniques, and Measurements for Atmospheric Remote Sensing VIII, 85340I; doi:10.1117/ 12.970616.

Feng, Y., V. Ramanathan, and V. R. Kotamarthi. 2013. "Brown Carbon: A Significant Atmospheric Absorber of Solar Radiation?" Atmospheric Chemistry and Physics 13: 8607-8621. doi:10.5194/ acp-13-8607-2013.

Fenn, R. W., S. A. Clough, W. O. Gallery, R. E. Good, F. X. Kneizys, J. D. Mill, L. S. Rothman, E. P. Shettle, and F. E. Volz. 1985. "Optical and Infrared Properties of the Atmosphere." In Handbook of Geophysics and the Space Environment, edited by Adolph S. Jursa, Air force geography laboratory.

Funk, C. C., J. Theiler, D. A. Roberts, and C. C. Borel. 2001. "Clustering to Improve Matched Filter Detection of Weak Gas Plumes in Hyperspectral Thermal Imagery." IEEE Transactions on Geoscience and Remote Sensing 39 (7): 1410-1420. doi:10.1109/36.934073.

Green, R. O., V. Carrère, and J. E. Conel. 1990. "Measurement of Atmospheric Water Vapor Using the Airborne Visible/Infrared Imaging Spectrometer (AVIRIS)". Imaging Processing '89, Am. Soc. Photogramm. and Remote Sensing, 31-44. Reno, Nevada, 23-26 April 1989.

Green, R. O., M. L. Eastwood, C. M. Sarture, T. G. Chrien, M. Aronsson, B. J. Chippendale, J. A. Faust, et al. 1998. "Imaging Spectroscopy and the Airborne Visible/Infrared Imaging Spectrometer (AVIRIS)". Remote Sensing of Environment 65: 227-248. doi:10.1016/S0034-4257(98)00064-9.

Hamlin, L., R. O. Green, P. Mouroulis, M. Eastwood, I. McCubbin, D. Wilson, D. Randall, M. Dudik, and C. Paine. 2010. "Imaging Spectrometer Science Measurements for Terrestrial Ecology: AVIRIS and the Next Generation AVIRIS Characteristics and Development Status". NASA Earth Science Technology Conference (2010). At the Sheraton Crystal City in Arlington, VA,June 22-24, 2010.

Hang, R., Q. Liu, G. Xia, and H. Song. 2018. "Correcting MODIS Aerosol Optical Depth Products Using a Ridge Regression Model." International Journal of Remote Sensing 39 (10): 3275-3286. doi:10.1080/01431161.2018.1439597.

Hanna, S. R., G. A. Briggs, and R. P. Hosker Jr. 1982. Handbook on Atmospheric Diffusion. United States: Technical Information Center, US Department of energy.

Herbin, H., and P. Dubuisson. 2016. Observation infrarouge de l'atmosphère terrestre [Infrared Observation of the Terrestrial Atmosphere]. London : ISTE editions, cop. 2016.

Hess, M., P. Koepke, and I. Schult. 1998. "Optical Properties of Aerosols and Clouds: The Software Package OPAC." Bulletin of the American Meteorological Society 79: 831-844. doi:10.1175/15200477(1998)079<0831:OPOAAC>2.0.CO;2.

Hoffer, A., A. Gelencsér, P. Guyon, G. Kiss, O. Schmid, G. P. Frank, P. Artaxo, and M. O. Andreae. 2006. "Optical Properties of Humic-Like Substances (HULIS) in Biomass-Burning Aerosols." Atmospheric Chemistry and Physics 6: 3563-3570. doi:10.5194/acp-6-3563-2006.

Hsu, N. C., R. Gautam, A. M. Sayer, C. Bettenhausen, C. Li, M. J. Jeong, S.-C. Tsay, and B. N. Holben. 2012. "Global and Regional Trends of Aerosol Optical Depth over Land and Ocean Using SeaWiFS Measurements from 1997 to 2010." Atmospheric Chemistry and Physics 12: 80378053. doi:10.5194/acp-12-8037-2012.

Irvine, W. M., and J. B. Pollack. 1968. "Infrared Optical Properties of Water and Ice Spheres." Icarus 8: 324-360. doi:10.1016/0019-1035(68)90083-3. 
Jacobson, M. Z. 2002. Atmospheric Pollution: History, Science, and Regulation. New York, NY: Cambridge University Press.

Jeong, M. J., Z. Li, D. A. Chu, and S.-C. Tsay. 2003. "Inter-Comparison and Synergy between the Two Long-Term Global Aerosol Products Derived from AVHRR and TOMS". Thirteenth ARM Science Team Meeting Proceedings, Broomfield, CO. March 31-April 4, 2003.

Kaufman, Y. J. 1987. "Satellite Sensing of Aerosol Absorption." Journal of Geophysical Research Atmospheres 92: 4307-4317. doi:10.1029/JD092iD04p04307.

Kaufman, Y. J., D. Tanré, and O. Boucher. 2002. "A Satellite View of Aerosols in the Climate System." Nature 419: 215-223. doi:10.1038/nature01091.

King, M., Y. J. Kaufman, D. Tanré, and T. Nakajima. 1999. "Remote Sensing of Tropospheric Aerosols from Space: Past, Present and Future." Bulletin of the American Meteorological Society 80 No. 11: 2229-2259.

Kneizys, F. X., L. W. Abreu, G. P. Anderson, J. H. Chetwynd, E. P. Shettle, A. Berk, L. S. Bernstein, et al. 1996. "The MODTRAN 2/3 Report and LOWTRAN 7 Model." Technical report. Prepared by Ontar Corporation for PL/GPOS.

Koller, E. 2015. Traitement Des Pollutions Industrielles. Eaux, Air, Déchets, Sols, Boues (2 Édition). Paris: Coll. Technique \& Ingénierie, L'Usine Nouvelle, Dunod.

Kruse, F. A., A. B. Lefkoff, J. W. Boardman, K. B. Heidebrecht, A. T. Shapiro, P. J. Barloon, and A. F. H. Goetz. 1993. "The Spectral Image Processing System (SIPS) - Interactive Visualization and Analysis of Imaging Spectrometer Data." Remote Sensing of Environment 44: 145-163. doi:10.1016/0034-4257(93)90013-N.

Leitão, J., A. Richter, M. Vrekoussis, A. Kokhanovsky, Q. J. Zhang, M. Beekmann, and J. P. Burrows. 2010. "On the Improvement of $\mathrm{NO}_{2}$ Satellite Retrievals - Aerosol Impact on the Airmass Factors." Atmospheric Measurements Techniques 3: 475-493. doi:10.5194/amt-3-475-2010.

Levy, R. C., S. Mattoo, L. A. Munchak, L. A. Rember, A. M. Sayer, and N. C. Hsu. 2013. "The Collection 6 MODIS Aerosol Products over Land and Ocean." Atmospheric Measurement Techniques 6: 159259. doi:10.5194/amtd-6-159-2013.

MacQueen, J. 1957. "Some Methods for Classification and Analysis of Multivariate Observations." Proceedings of the Fifth Berkeley Symposium on Mathematical Statistics and Probability 1: 281297.

Marion, R., R. Michel, and C. Faye. 2004. "Measuring Trace Gases in Plumes from Hyperspectral Remotely Sensed Data." IEEE Transactions on Geoscience and Remote Sensing 42 (4): 854-864. doi:10.1109/TGRS.2003.820604.

Masclet, P. 2005. Pollution Atmosphérique (Causes, Conséquences, Solutions, Perspectives). Coll. Technosup, Ellipses, Paris.

Mie, G. 1908. "Beiträge Zur Optik Trüber Medien, Speziell Kolloidaler Metallösungen." Annalen Der Physik 25 (3): 377-445. doi:10.1002/andp.19083300302.

Ocko, I. B., V. Ramaswamy, P. Ginoux, Y. Ming, and L. Horowitz. 2012. "Sensitivity of Scattering and Absorbing Aerosol Direct Radiative Forcing to Physical Climate Factors." Journal of Geophysical Research 117. doi:10.1029/2012JD018019.

Penning de Vries, M. J. M., S. Beirle, C. Hörmann, J. W. Kaiser, P. Stammes, L. G. Tilstra, O. N. E. Tuinder, and T. Wagner. 2015. "A Global Aerosol Classification Algorithm Incorporating Multiple Satellite Data Sets of Aerosol and Trace Gas Abundances." Atmospheric Chemistry and Physics 15: 10597-10618. doi:10.5194/acp-15-10597-2015.

Pujol, O., G. Brogniez, and L. Labonnote. 2012. "Simplification for Fraunhofer Diffracting Pattern of Various Randomly Oriented Ice Crystals in Cirrus." Journal of the Optical Society of America A 29 (9): 2015-2018. doi:10.1364/JOSAA.29.002015.

Quinn, P. K., S. F. Marshall, T. S. Bates, D. S. Covert, and V. N. Kapustin. 1995. "Comparison of Measured and Calculated Aerosol Properties Relevant to the Direct Radiative Forcing of Tropospheric Sulfate Aerosol on Climate." Journal of Geophysical Research 100 (5): 8977-8991. doi:10.1029/95JD00387.

Riffler, M., C. Popp, A. Hauser, F. Fontana, and S. Wunderle. 2010. "Validation of a Modified AVHRR Aerosol Optical Depth Retrieval Algorithm over Central Europe." Atmospheric Measurement Techniques 3: 1255-1270. doi:10.5194/amt-3-1255-2010. 
Shimoni, M., R. Heremans, F. D. Van Der Meer, and M. Acheroy. 2007. "Measuring Pollutant Gases Using VNIR and TIR Imaging Spectroscopy". Proceedings of the $5^{\text {th }}$ EARSeL SIG IS Workshop on Imaging Spectroscopy: Innovation in environmental research, Bruges, Belgium, 1-11. April 2325, 2007.

Thorpe, A. K., D. A. Roberts, E. S. Bradley, C. C. Funk, P. E. Dennison, and I. Leifer. 2013. “High Resolution Mapping of Methane Emissions from Marine and Terrestrial Sources Using a ClusterTuned Matched Filter Technique and Imaging Spectrometry." Remote Sensing of Environment 134: 305-318. doi:10.1016/j.rse.2013.03.018.

Thorpe, A. K., D. A. Roberts, P. E. Dennison, E. S. Bradley, and C. C. Funk. 2012. "Point Source Emissions Mapping Using the Airborne Visible/Infrared Imaging Spectrometer (AVIRIS)." Proc. SPIE 8390, Algorithms and Technologies for Multispectral, Hyperspectral, and Ultraspectral Imagery XVIII, 839013; doi: 10.1117/12.918958.

Veefkind, J. P., K. F. Boersma, J. Wang, T. P. Kurosu, N. Krotkov, K. Chance, and P. F. Levelet. 2011. "Global Satellite Analysis of the Relation between Aerosols and Short-Lived Trace Gases." Atmospheric Chemistry and Physics 11: 1255-1267. doi:10.5194/acp-11-1255-2011.

Vidot, J. 2005. "Télédétection des aérosols au-dessus des terres émergées à l'aide des capteurs 'couleur de l'eau' et applications." Ph.D. thesis, Université du Littoral Côte d'Opale, France.

Vincent, J. H. 1995. Aerosol Science for Industrial Hygienists. Oxford, United Kingdom: Elsevier Science.

Weickmann, H. K., and H. J. aufm Kampe. 1953. "Physical Properties of Cumulus Clouds." Journal of Meteorology 10: 204-211. doi:10.1175/1520-0469(1953)010<0204:PPOCC>2.0.CO;2.

Wen, C. S. 1996. The Fundamentals of Aerosols Dynamics. Singapore: World Scientific.

Winker, D. M., J. Pelon, J. A. Coakley Jr., S. A. Ackerman, R. J. Charlson, P. R. Colarco, P. Flamant, et al. 2010. "The CALIPSO Mission: A Global 3D View of Aerosols and Clouds." Bulletin of American Meteorological Society 91 (9): 1211-1229. doi:10.1175/2010BAMS3009.1. 